\title{
Multiresponse Optimization of a Compliant Guiding Mechanism Using Hybrid Taguchi-Grey Based Fuzzy Logic Approach
}

\author{
Thanh-Phong Dao ${ }^{1,2}$ \\ ${ }^{1}$ Division of Computational Mechatronics, Institute for Computational Science, Ton Duc Thang University, \\ Ho Chi Minh City 700000, Vietnam \\ ${ }^{2}$ Faculty of Electrical \& Electronics Engineering, Ton Duc Thang University, Ho Chi Minh City 700000, Vietnam
}

Correspondence should be addressed to Thanh-Phong Dao; daothanhphong@tdt.edu.vn

Received 1 November 2015; Revised 4 April 2016; Accepted 12 April 2016

Academic Editor: Chunlin Chen

Copyright (C) 2016 Thanh-Phong Dao. This is an open access article distributed under the Creative Commons Attribution License, which permits unrestricted use, distribution, and reproduction in any medium, provided the original work is properly cited.

\begin{abstract}
Because of a lack of precisely miniaturized guiding mechanism, micro/nanoindentation devices are now difficult to integrate inside scanning electron microscope. A compliant guiding mechanism (CGM) with a compact size, serving as an accurate positioning platform, is hence proposed in this paper. The displacement and first natural frequency are the most important quality responses of CGM. The geometric parameters of CGM and applied force play a vital role in determining those responses. The experiment plan is firstly designed by Taguchi's $L_{27}$ orthogonal array. A hybrid approach of Taguchi-grey based fuzzy logic is then developed to optimize two responses, simultaneously. The grey relational analysis based on the fuzzy logic is used to achieve a grey-fuzzy reasoning grade (GFRG) that combines all the quality characteristics. The GFRG, serving as a performance index, determines optimal parameter levels. Analysis of variance is conducted to assess the significant parameters affecting the responses. The confirmation results revealed that the $195 \mu \mathrm{m}$ displacement of the CGM was many times greater than that of the previous mechanisms. It could be concluded that the quality responses of CGM can be significantly improved through the hybrid optimization approach. The proposed methodology has great applications for related compliant mechanisms and engineering sciences. Taking benefits of a compact structure into account, CGM has a great ability for micro/nanoindentation device inside scanning electron microscope.
\end{abstract}

\section{Introduction}

Micro/nanoindentation technique now serves as an efficient tool to probe the mechanical properties of materials. It can test the hardness, crack length, fracture onset, creep, Young's modulus, crack propagation, shear band formation, plastic deformation, pile-up, sink-in, and so forth. This technique has been commonly used in various fields of material science, semiconductor, biomechanics, biomedicines, surface engineering, civil, and micro/nanoelectromechanical systems.

For example, the mechanical properties and buckling of single-crystal nanolines were tested under indentation [1]. The deduced elastic property of carbon nanotubes was also investigated via indentation [2]. The indentation was utilized to determine the fatigue strength of S38C steel [3]. Via finite element simulations, the pile-up on accuracy of sharp indentation test was demonstrated [4]. The Vickers microhardness of boron suboxide ceramics was measured via indentation [5]. The microindentation for human tooth enamel and dentine was performed [6]. The creep stress exponent from indentation data was studied [7]. The fracture toughness was investigated through indentation [8]. The indentation simulation was conducted for reverse analyses in depth-sensing [9]. Few years later, an in situ nanoindentation device was designed [10]. The Vickers microindentation was studied to assess the materials microhardness [11]. The behavior of bone was simulated via indentation [12]. Ciofu and Crețu [13] discovered the behaviors of ultramid plastic materials via microindentation. The microindentation was applied for estimating the fracture toughness of Al6061-T6 [14]. The fracture and plastic deformation were monitored using indentation [15]. The Berkovich, Vickers, and conical indentation tests were compared via numerical simulations [16]. The deformation behavior and mechanical properties of 
polycrystalline and single crystal alumina were studied via nanoindentation [17].

It is known that the indentation technique offers many advantages over conventional tests such as reduced cost, economy in material and time, simplified experimentation, capacity to discover an inhomogeneous surface for microstrength variations, and residual stress [1-17]. However, most of available indentation instruments have complicated structures, frameworks, and large volumes. Those instruments are therefore extremely difficult to insert inside the scanning electron microscope (SEM), the transmission electron microscope (TEM), the image analysis, and so forth, because the SEM and TEM have a small volume chamber, short working distance, electromagnetic sensing, vacuum environment, and vibration sensing [18-20].

Regarding the positioning accuracy, a precise guiding mechanism is actually necessary for indentation device. This mechanism aims to drive a sample towards a fixed indenter. In the other words, it should possess a positioning capacity within the range of a few hundreds of micro/nanometers. To fulfill that requirement, designing a precise guiding mechanism with a compact size is now difficult chances for academic scientists, engineer, and manufacturers.

Up till now, traditional rigid-link mechanisms cannot meet the accurate positioning requirements due to friction in kinematic pairs, need for lubricant, maintenance, assembly, backlash, and so on. On the contrary, compliant mechanism gains the mobility from the deflection of flexure hinges rather than from kinetic joints. It offers several extra advantages such as smooth displacement, no backlash, zero friction, no need for lubricant, no noise, part-count reduction, simplified manufacturing processes, increased precision and reliability, reduced wear and weight, decreased assembly time and maintenance, and monolithic structure manufactured by electrical discharged machining or wire electrical discharged machining [21]. As a result of the accurate requirement, compliant mechanism is a potential candidate for positioning system.

From such analysis, a compliant guiding mechanism (CGM) is designed in this study. Taking advantage of a compact size into account, this mechanism can serve as a precise positioning platform inside a microindentation device. The microindentation device is composed of key components such as CGM, axis coarse positioner, indenter holder, displacement sensor, and load cell. The CGM is the most important element to construct a good indentation system.

The working efficiency of CGM is assessed with consideration of two quality characteristics such as the displacement and first natural frequency. Because the CGM has a large displacement, the indentation depth is then broadened. Moreover, the CGM has a high first natural frequency; the responding speed of the indentation device is also faster. In compliant mechanisms, a large displacement is always conflicted with a high frequency [21]. From another aspect, these quality responses may be affected by controllable parameters such as the force exerting the CGM and the geometric parameters. A suitable optimization approach is actually needed to achieve a satisfaction for both responses, simultaneously. The optimization process of CGM is based on design of experiments, and thus experiment-based optimization methods are taken into consideration in this study.

Recently, the Taguchi method has been extensively used for optimizing in various engineering fields due to decreased number of experiments [22]. Even though the Taguchi method was successfully proven for optimizing a single performance characteristic $[23,24]$, but it failed for optimizing multiple performance characteristics $[25,26]$. As a result, a hybrid approach is needed to resolve multiresponse optimization problems.

In the past, initialized by Deng [27], the grey relational analysis has been useful technique in dealing with poor, incomplete, and partial known data [28]. The hybrid Taguchibased grey relational analysis was discovered for optimizing multiple characteristics in different fields of manufacturing [29-32]. An earlier method, the fuzzy logic, was originated by Zadeh [33], which was used for dealing with uncertain and vague information. This theory was developed for many different fields. For instance, Chen et al. [34] constructed the probabilistic fuzzy logic for the partial feedback of the robust control of quantum systems. Also, Chen and Xiao [35] applied the probabilistic fuzzy logic for mobile robots and for the mobile-robot reactive navigation [36]. And then a neural-fuzzy formation controller was investigated for the multiagent systems [37]; however, the fuzzy logic rules may not be easily amendable to dynamic changes of a process $[38,39]$.

To compensate the defect of fuzzy logic, the grey relational analysis was integrated with the fuzzy logic in the multivariate system to obtain the best quality responses [4044]. The grey relational analysis has three types such as the lower-the better, the higher-the better, and the nominalthe better, which contain certain degree of uncertainty and vagueness better than the fuzzy logic. For example, the grey theory was successfully applied for multiobjective optimization of milling [45], injection-molded part with a thin shell feature [46], CNC turning process [47], and so forth. Taking the advantages of the Taguchi method into account, grey relational analysis, and fuzzy logic, a hybrid approach of the Taguchi-grey based fuzzy logic was applied usefully for multiresponse optimization problems [48]. However, this hybrid approach has not been developed for compliant mechanisms yet, especially for a compliant guiding mechanism of indentation device.

The objective of this study is to propose a multiresponse optimization for a compliant guiding mechanism (CGM). The CGM with flexure hinges serves as a precise positioning mechanism. It is a major part of indentation device inside the SEM. A hybrid approach of the Taguchi-grey based fuzzy logic is developed to maximize the displacement and first natural frequency of CGM, simultaneously. The force exerting CGM and geometric parameters of flexure hinge are considered as design variables. The experiment layout is assigned by Taguchi's $L_{27}$ orthogonal array. As suggested by the Taguchi method, the response table and response graph are constructed to determine the optimal parameter levels. Furthermore, the analysis of variance (ANOVA) is used to 

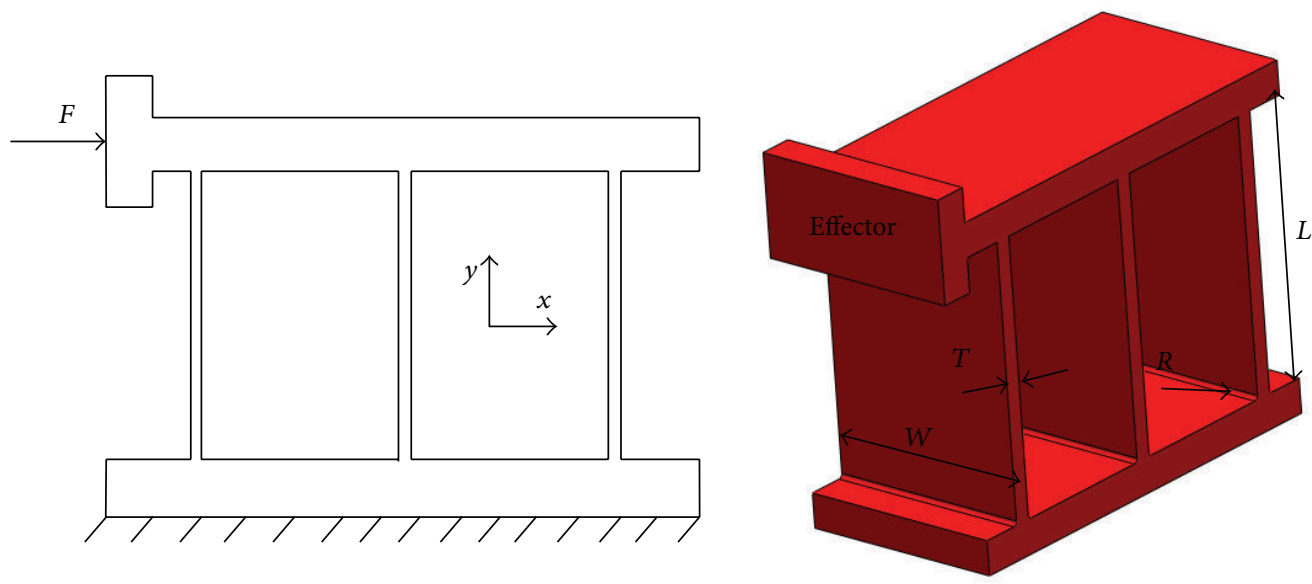

FIGURE 1: Proposed model of compliant guiding mechanism (CGM).

recognize the significant parameter affecting the responses. Finally, the experiments are conducted to validate the optimal results.

\section{Design, Analysis, and Optimization Statement}

2.1. Design Description of Guiding Compliant Mechanism. Regarding micro/nanoindentation devices inside SEM, a precise guiding mechanism is really needed to bring a sample towards a fixed indenter. As mentioned, compliant mechanisms can fulfill the requirements of precise guiding mechanism [21].

In this study, a compliant guiding mechanism (CGM) was designed via the use of flexure hinges. The CGM is aimed at serving as a precise positioning platform. The CGM included a fixed base, an end effector, and three flexure hinges with rectangular cross sections, as depicted in Figure 1. The CGM was constructed to achieve the single-axis translation along the $x$-direction. Compared with other hinges, the rectangular cross-sectional flexure hinges were chosen for CGM because of making a larger displacement [21]. Because the CGM has a compact size, the indentation device is therefore capable of integrating inside the SEM chamber.

As seen in Figure 1, under the force $F$ exerted on the effector from an appropriate actuator, the CGM would translate along the $x$-direction. To obtain a single-axis translation for the proposed CGM, the following constraints should be satisfied:

$$
\begin{aligned}
& W \geq 10 T, \\
& L \geq 12.5 T,
\end{aligned}
$$

where $W$ is the width, $L$ is the length, and $T$ is the thickness of the flexure hinges.
The constraint in (1) was the locking of the corresponding transverse flexion of the CGM, while the constraint in (2) allowed flexibility of the CGM along the direction of applied force. However, dynamic loads frequently encountered during its stroke lead to decreased life. On the other hand, a high stress concentration at the fixed end of the flexure hinges led to reduced fatigue life and increased mechanical failure [21]. To reduce the stress concentration and improve performances, the CGM was designed with a filleted radius $R$ at the fixed ends of the flexure hinges. In this paper, all flexure hinges were designed with the same dimensions. Moreover, to avoid and limit parasitic motion along the $y$-direction, a symmetric structure for the CGM was suggested.

The CGM, monolithically fabricated via wire electrical discharged machining process, can reduce an extra assembly for the indentation device. The performance efficiency of indentation device is assessed by a broad displacement and a fast responding speed. As explained, when the CGM has a large displacement, the indentation depth will be improved. Besides, the CGM has a high first natural frequency; the responding speed of the device is also faster. The quality responses of CGM can be enhanced by an appropriate optimization methodology. On the other hand, the optimal design of flexure hinge's parameters is needed to achieve the best quality responses of CGM.

Material of aluminum alloy 6061-T651 was chosen for the GCM due to its excellent mechanical properties such as the high yield strength of $780 \mathrm{MPa}$, Young's modulus of $210 \mathrm{GPa}$, light density of $7850 \mathrm{~kg} / \mathrm{m}^{3}$, and Poisson's ratio of 0.3 .

To sum up, the CGM design was based on the principle of the compliant mechanism with flexure hinge. The quality responses of CGM were measured via the displacement and first natural frequency. To improve those characteristics, the geometric parameters of flexure hinge would be optimized by a hybrid optimization approach.

2.2. Analysis of Parasitic Motion. The parasitic motion is an undesired error for any single-axis positioning mechanism because it reduces the positioning accuracy of indentation 
device. Hence, this error would be regarded during the design phase.

A finite element analysis (FEA) is now widely used to realize performance characteristics of complex structures before real manufacturing. Similarly, this study would evaluate the correlation between the displacement along the $x$-axis and the parasitic motion error along the $y$-axis via FEA through ANSYS software package [49].

To perform this analysis, the eleven simulations were conducted by ANSYS 2015. And then the displacement and parasitic motion error were collected. The ratio (\%) of the parasitic error $\left(p_{\mathrm{e}}\right)$ to the displacement $\left(d_{i}\right)$ was calculated. The results showed that these ratios were less than $1.4 \%$, as seen in Table 1. To sum up, the design of CGM was well satisfied with (1) and (2). It could be concluded that the CGM is capable of translating along the $x$-direction well. The CGM could serve as an excellent positioning platform for indentation device.

2.3. Effect of Design Variables on Quality Responses. Considering the effects of design parameters to the quality responses of CGM, many FEA simulations were carried out. Usually, to illustrate those effects, a parameter's value will be changed in the specific range while the others are remained constantly. However, this way actually spent much time because of constructing a model in a CAD software, and then that model is imported into ANSYS to be analyzed.

Unlike such a way, the response surface method (RSM) in ANSYS [49] was adopted as a statistical regression model to illustrate the effect of design variables on the displacement and the first natural frequency.

In the first phase, the 3D model of CGM was directly created in the design modeler module of ANSYS 2015. Subsequently, the five input parameters consisting of the force $F$, length $L$, width $W$, thickness $T$, and filleted radius $R$ were marked as parametric input variables. At the same time, the displacement and first natural frequency were also marked as parametric output variables. To perform this computational analysis, assuming that the force was in the range at $180.0 \mathrm{~N}$ to $180.4 \mathrm{~N}$, the length was in the range from $40.0 \mathrm{~mm}$ to $40.4 \mathrm{~mm}$; the width was in the range from $30.0 \mathrm{~mm}$ to $30.4 \mathrm{~mm}$; the thickness was in the range from $2.2 \mathrm{~mm}$ to $2.6 \mathrm{~mm}$, and the filleted radius was in the range from $0.4 \mathrm{~mm}$ to $0.8 \mathrm{~mm}$.

To realize a good regression model, many criteria have been regarded. Based on the computational results via RSM, as in Table 2, the regression model for the computational analysis was evaluated as follows: (1) $R^{2}$ is a coefficient of determination (best value $=1$ ), (2) $\mathrm{MRR}$ is a maximum relative residual (best value $=0 \%$ ), (3) RMSE is a root mean square error (best value $=0$ ), (4) RRMSE is a relative root mean square error (best value $=0 \%),(5)$ RMAE is a relative maximum absolute error (best value $=0 \%$ ), and (6) RAAE is a relative average absolute error (best value $=0 \%$ ). The results revealed that these parameters are almost the best for the computational regression model in this study. Hence, the relationship between the input and the output parameters was established properly.
TABLE 1: Displacement, parasitic error, and ratio of $p_{\mathrm{e}} / d_{i}$.

\begin{tabular}{lccc}
\hline Number & $\begin{array}{c}\text { Displacement } \\
d_{i}(\mathrm{~mm})\end{array}$ & $\begin{array}{c}\text { Parasitic } \\
\text { error } p_{\mathrm{e}} \\
(\mathrm{mm})\end{array}$ & Ratio of $p_{\mathrm{e}} / d_{i}(\%)$ \\
\hline 1 & 0.11232 & 0.00141 & 1.26 \\
2 & 0.12978 & 0.00155 & 1.19 \\
3 & 0.12896 & 0.00148 & 1.15 \\
4 & 0.13090 & 0.00162 & 1.24 \\
5 & 0.13091 & 0.0016 & 1.22 \\
6 & 0.12891 & 0.00154 & 1.19 \\
7 & 0.12823 & 0.00150 & 1.17 \\
8 & 0.13104 & 0.00171 & 1.30 \\
9 & 0.08983 & 0.00111 & 1.24 \\
10 & 0.19508 & 0.00241 & 1.24 \\
11 & 0.12970 & 0.00162 & 1.25 \\
\hline
\end{tabular}

TABLE 2: Goodness of fit of the regression model.

\begin{tabular}{lc}
\hline Parameters & Value \\
\hline$R^{2}$ & 1 \\
MRR & 0 \\
RMSE & $10^{-12}$ \\
RRMSE & 0 \\
RMAE & 0 \\
RAAE & 0 \\
\hline
\end{tabular}

TABLE 3: Coded levels of the design variables.

\begin{tabular}{lcccccc}
\hline \multirow{2}{*}{ Factors } & \multirow{2}{*}{ Unit } & \multicolumn{5}{c}{ Coded levels } \\
& & -2 & -1 & 0 & 1 & 2 \\
\hline$F$ & $\mathrm{~N}$ & 180.0 & 180.05 & 180.10 & 180.15 & 180.40 \\
$L$ & $\mathrm{~mm}$ & 40.0 & 40.10 & 40.20 & 40.30 & 40.40 \\
$W$ & $\mathrm{~mm}$ & 30.0 & 30.10 & 30.20 & 30.30 & 30.40 \\
$T$ & $\mathrm{~mm}$ & 2.20 & 2.30 & 2.40 & 2.50 & 2.60 \\
$R$ & $\mathrm{~mm}$ & 0.40 & 0.50 & 0.60 & 0.70 & 0.80 \\
\hline
\end{tabular}

The range unit of each input parameter is not the same; even their values are unlike. Thus, to facilitate illustrating the relationship between inputs and outputs on the same plot, each level of all input parameters was coded to be similar. The coded levels for the design variables are given in Table 3, with consideration of the effects of the design variables on the output parameters in only one plot. As shown in Figure 2, when each of the five design variables changed its value, the displacement would be varied. The thickness especially strongly affected the displacement. The results revealed that all the five design variables had a direct influence on displacement. Using the same computational method, the input parameters also relatively affected the frequency, as seen in Figure 3.

Most of the curves of Figures 2 and 3 were the nonlinear profiles. It could be concluded that the significant parameters, the force $F$, the length $L$, the width $W$, the thickness $T$, and the filleted radius $R$ directly affected the two quality 


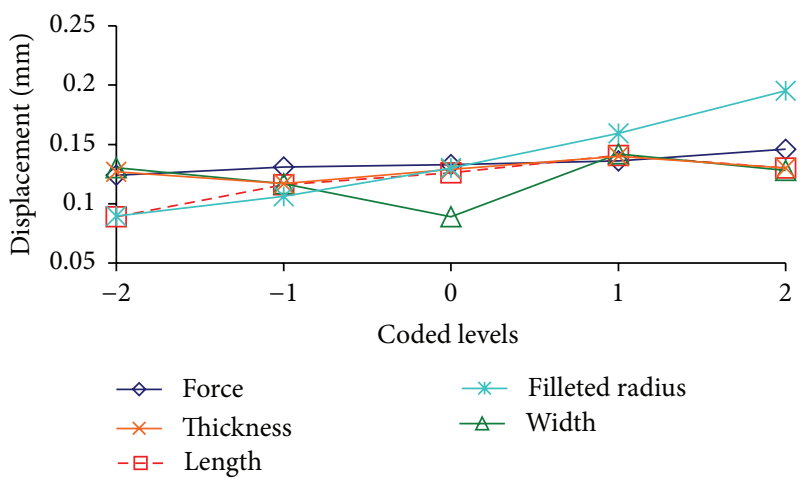

FIGURE 2: Relationship between the input parameters and displacement.

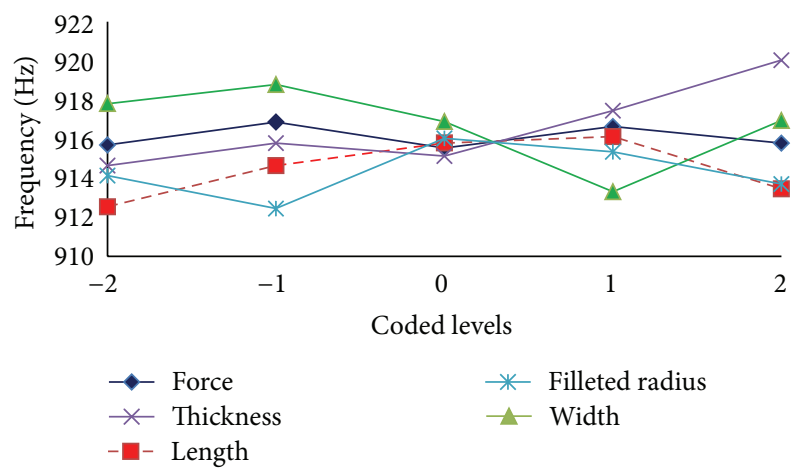

FIGURE 3: Relationship between the input parameters and frequency.

responses. Hence, these parameters would be considered in further optimization process.

2.4. Optimization Statement. The objective of the CGM was to provide a large displacement and a high first natural frequency. These quality responses would be achieved through a suitable optimization process. The multiresponse optimization problem for CGM was briefly formulated as follows.

Find

$$
F, L, T, W, R
$$

Maximize displacement:

$$
y_{1}(F, L, T, W, R) \text {. }
$$

Maximize first natural frequency

$$
y_{2}(F, L, T, W, R)
$$

subject to constraints

$$
\sigma_{\max } \leq \frac{\sigma_{y}}{\mathrm{SF}}
$$

within ranges

$$
\begin{gathered}
180.0 \mathrm{~N} \leq F \leq 180.4 \mathrm{~N}, \\
40.0 \mathrm{~mm} \leq L \leq 40.4 \mathrm{~mm}, \\
30.0 \mathrm{~mm} \leq W \leq 30.4 \mathrm{~mm}, \\
2.2 \mathrm{~mm} \leq T \leq 2.6 \mathrm{~mm}, \\
0.4 \mathrm{~mm} \leq R \leq 0.8 \mathrm{~mm},
\end{gathered}
$$

where the objective functions $y_{1}$ and $y_{2}$ are measures of the displacement and the first natural frequency, respectively. They depend on applied force $F$, length $L$, width $W$, thickness $T$, and filleted radius $R . \sigma_{\max }$ is the maximum equivalent stress, $\sigma_{y}$ is the yield strength of the proposed material, and $\mathrm{SF}$ is the safety factor.

Usually, any compliant mechanism also operates in the elastic area of a specific material [21]. To avoid plastic failures, a safety factor as large as possible should be selected to be safe at the hinges. In this study, a safety factor of 3 was chosen for the CGM. The design variables were assigned in the range of (7) due to the following reasons: (i) if the length $L$ is lower than $40.0 \mathrm{~mm}$, the displacement will be decreased, and if $L$ is larger than $40.4 \mathrm{~mm}$, the size of CGM will be increased; (ii) if the width $W$ is greater than $30.4 \mathrm{~mm}$, the mass of the CGM can increase, and if $W$ is smaller than $30.0 \mathrm{~mm}$, the stiffness of CGM will be decreased; (iii) if the thickness $T$ is thicknesses is lower than $0.4 \mathrm{~mm}$, the displacement will be increased but the frequency decreased, and if $T$ is larger than $0.8 \mathrm{~mm}$, the proposed mechanism will become stiffer; the displacement will be decreased; (iv) the range of filleted radius $R$ is selected to avoid the stress concentration at the flexure hinge. To sum up, the lower bounds for the parameters were selected to guarantee a good compliance, and the upper bounds of the geometric dimensions were set to achieve a compact structure.

\section{Methodology}

In general, mathematical models should be formulated prior to an optimization process; however, if modeling errors from mathematical models become large, optimal results will be unacceptable. To eliminate that limitation, an optimization process for CGM was based on the experimental procedure. With miniaturized number of experiments, the Taguchi method was the most appropriate robust approach. As mentioned, the Taguchi method only optimized a single objective; it was hence coupled with others to optimize multiple objectives.

In this study, a hybrid Taguchi-grey based fuzzy logic approach was developed to serve as an effective multiresponse optimization tool for the CGM. It got a fuzzy rules procedure rather than making traditional grey relational analysis (GRG) estimation for grey relational analysis. Using the GRG estimation, the optimal quality responses were obtained $[29,30]$. On the contrary, the fuzzy inference system (FIS) was used in this study to estimate the GRG. FISs were also defined as fuzzy-rule-based systems, fuzzy models, and fuzzy associative memories. Figure 4 shows a systematic 


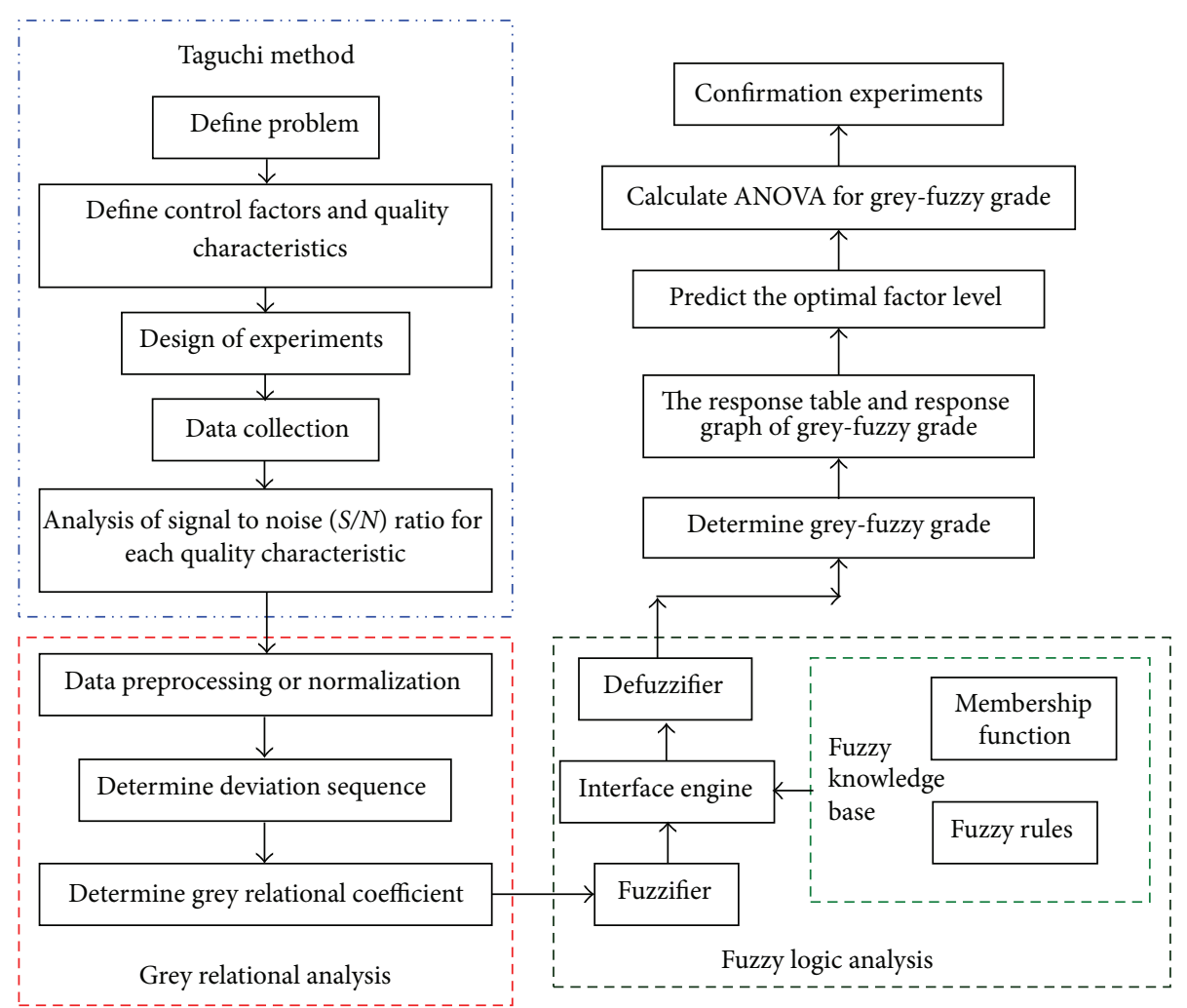

FIGURE 4: The flowchart of multiresponse optimization approach.

flowchart for the multiresponse optimal procedure using a hybrid Taguchi-grey based fuzzy logic approach. The optimization process was divided into key steps as follows.

Firstly, Steps 1-5 were based on Section 2.3 and the Taguchi method to identify optimization problem, design of experiments, and measurement of quality characteristics.

Secondly, Steps 6-8 were applied to the grey relational analysis. The grey relational analysis was carried out through sequence groups.

Lastly, Steps 9-13 were a development of the greyfuzzy reasoning analysis. The fuzzy logic system was herein integrated with the grey relational analysis. The fuzzier used the membership functions to fuzzify the grey relational coefficient (GRC) of each quality performance. The fuzzy rules (if-then control rules) were generated and defuzzifier converted fuzzy predicted value into a grey-fuzzy reasoning grade (GFRG). The response graph and table response were established, and then the optimal parameter levels were determined. Analysis of variance was employed to determine the most significant parameter affecting the quality responses. Then the optimal grey-fuzzy reasoning grade was identified. The final phase was a validation of the optimal results through confirmation experiments.

Step 1 (define problem). The purpose of this study was the optimal design for compliant guiding mechanism. The quality objectives of CGM were to maximize the displacement and maximize the first natural frequency, simultaneously.
Step 2 (define control factors and quality characteristics). As previous analysis, the force $F$, length $L$, width $W$, thickness $T$, and filleted radius $R$ were the important factors affecting the quality objectives (the displacement and first natural frequency).

Step 3 (design of experiments using the orthogonal array of Taguchi method). To investigate the entire design parameters with a small number of experiments, the Taguchi method with special orthogonal array was employed for the experimental layout, as compared with a full factorial approach [22].

Step 4 (experimental data collection). Data of the displacement and first natural frequency were measured by many experiments in real.

Step 5 (analysis of signal to noise $(S / N)$ ratio for each quality characteristic). The $S / N$ ratio $(\eta)$ for various responses was calculated via the Taguchi method. According to the Taguchi method [22], three types of characteristic are considered as follows: the lower-the better, the higher-the better, and the nominal-the better. Because the displacement and first natural frequency were expected to obtain the maximum values, the higher-the better was hence selected, which was described as follows [28]:

$$
\eta=-10 \log \left(\frac{1}{n} \sum_{i=1}^{n} \frac{1}{y_{i}^{2}}\right),
$$


where $\eta$ is the signal to noise ratio in decibels. $y_{i}$ is the measured response value of $i$ th experiment. $n$ denotes the number of experiments. Equation (8) was applied for both responses.

Step 6 (data preprocessing or normalization). To avoid the effect of different units and to reduce the variability, data preprocessing or normalization was a necessary step in the grey relational analysis [42-44]. Data preprocessing was transferring of the original sequence to a comparable sequence in the range from zero to one, which means that the given data sequence is transferred into a dimensionless data sequence.

In this study, the normalized $S / N$ ratio $z_{i}(k)$ value for $n$ experiments was calculated to adjust the measured values on different scales to a common scale. The type of the higherthe better was used for both quality responses; hence, the normalization equation for the $S / N$ ratio for both quality responses was computed as follows:

$$
z_{i}(k)=\frac{\eta_{i}(k)-\min \eta_{i}(k)}{\max \eta_{i}(k)-\min \eta_{i}(k)},
$$

where $z_{i}(k)$ is the normalized $S / N$ value for the $k$ th response $(k=1,2, \ldots, m)$ in the $i$ th experiment (known as the comparability sequence of $S / N$ data); $\eta_{i}(k)$ indicates the estimated $S / N$ value (known as the original sequence of $S / N$ ratio data); and $\max \eta_{i}(k)$ and $\min \eta_{i}(k)$ are the largest and smallest values of $\eta_{i}$, respectively.

Step 7 (determine deviation sequence). Before calculating the grey relational coefficient, the absolute deviation sequence $z_{o}(k)$ of the reference sequence and comparability sequence $z_{i}(k)$ must be determined. The absolute deviation sequence was calculated by the following equation [42-44]:

$$
\Delta_{o i}(k)=\left\|z_{o}(k)-z_{i}(k)\right\|,
$$

where $\Delta_{o i}(k)$ is the absolute difference sequence between $z_{o}(k)$ and $z_{i}(k) ; z_{o}(k)$ is the reference sequence that presents the ideal value (optimal value, generally equal to 1 in a normalized sequence) for the $k$ th response; and $z_{i}(k)$ is the comparability sequence.

Step 8 (determine grey relational coefficient). In the grey relational analysis, the grey relational coefficient (GRC) was calculated to give the relationship between the optimal and actual normalized experimental results [42-44]. In this study, the grey relational coefficient expressed the relationship between the best and the actual normalized $S / N$ ratios. The grey relational coefficient was computed as follows [42-44]:

$$
\gamma_{i}(k)=\frac{\Delta_{\min }+\delta \Delta_{\max }}{\Delta_{o i}(k)+\delta \Delta_{\max }}
$$

where $\gamma_{i}(k)$ is the grey relational coefficient; $\Delta_{\min }$ is the smallest value of $\Delta_{o i} ; \Delta_{\max }$ is the largest value of $\Delta_{o i}$; and $\delta$ is the distinguishing coefficient $(0 \leq \delta \leq 1)$ for adjusting the interval of $\gamma_{i}(k)$. In this study, $\delta$ of 0.5 was set for the average distribution due to the moderate distinguishing effects and good stability of outcomes.
Step 9 (grey-fuzzy reasoning analysis). In general, the basic structure of a fuzzy logic unit includes a fuzzifier, membership functions, a fuzzy rule base, an inference engine, and a defuzzifier. This study used the GRC value of displacement and the GRC value of first natural frequency as the input variables for the fuzzy inference system (FIS).

Next, the trapezoidal membership function was applied for fuzzification to achieve fuzzy sets. The fuzzy rules were then created in the inference engine to conduct fuzzy reasoning and obtain fuzzy values. Finally, the trapezoidal membership function was applied for defuzzification to obtain a multiresponse performance index (MPI). Fuzzy input variables and output variable used trapezoidal membership functions. The equation of trapezoidal membership functions was described as follows [50]:

$$
\mu_{A}(x, a, l, r, b)= \begin{cases}\frac{(x-a)}{(l-a)} & a \leq x \leq l \\ 1 & l<x<r \\ \frac{(x-b)}{(r-b)} & r \leq x \leq b,\end{cases}
$$

where $\mu_{A}$ represents the membership functions of the fuzzy set; $a, b, l$, and $r$ denote parameters; and $x$ is variable.

The fuzzy rule consisting of a group of if-then control rules was constructed for optimization process in this study. The fuzzy rule was developed with two inputs: $x_{1}$ denotes the grey relation coefficient value of displacement and $x_{2}$ represents the grey relation coefficient value of first natural frequency, and one output variable $y$ is denoted as MPI. Based on the previous 27 experiments as well as to enhance interpretability of fuzzy algorithm and to refine classifiers, this study established the nine fuzzy subsets for GRC of displacement: tiny (T), very small (VS), small (S), smallmedium (SM), medium (M), medium-large (ML), large (L), very large $(\mathrm{VL})$, and huge $(\mathrm{H})$; the three fuzzy subsets for GRC of frequency: small (S), medium (M), and large (L); and the nine fuzzy subsets for the MPI: tiny (T), very small (VS), small (S), small-medium (SM), medium (M), medium-large $(\mathrm{ML})$, large $(\mathrm{L})$, very large $(\mathrm{VL})$, and huge $(\mathrm{H})$. The 27 fuzzy rules for two inputs and one output were formed according to the concurrence that a large grey relational coefficient would be a better process response. These rules were developed to express the inference relationship between input and output. A set of rules were written for activating the FIS and the FIS was evaluated to predict the grey-fuzzy reasoning grade (GFRG) for all 27 experiments. The linguistic fuzzy rule was described as follows:

Rule 1: if $x_{1}$ is $A_{1}$ and $x_{2}$ is $B_{1}$, then $y$ is $C_{1}$ else Rule 2: if $x_{1}$ is $A_{2}$ and $x_{2}$ is $B_{2}$, then $y$ is $C_{2}$ else Rule 3: if $x_{1}$ is $A_{3}$ and $x_{2}$ is $B_{3}$, then $y$ is $C_{3}$ else Rule 4: if $x_{1}$ is $A_{4}$ and $x_{2}$ is $B_{4}$, then $y$ is $C_{4}$ else Rule 5: if $x_{1}$ is $A_{5}$ and $x_{2}$ is $B_{5}$, then $y$ is $C_{5}$ else Rule 6: if $x_{1}$ is $A_{6}$ and $x_{2}$ is $B_{6}$, then $y$ is $C_{6}$ else Rule 7: if $x_{1}$ is $A_{7}$ and $x_{2}$ is $B_{7}$, then $y$ is $C_{7}$ else Rule 8: if $x_{1}$ is $A_{8}$ and $x_{2}$ is $B_{8}$, then $y$ is $C_{8}$ else 
Rule 9: if $x_{1}$ is $A_{9}$ and $x_{2}$ is $B_{9}$, then $y$ is $C_{9}$ else Rule 10: if $x_{1}$ is $A_{10}$ and $x_{2}$ is $B_{10}$, then $y$ is $C_{10}$ else Rule 11: if $x_{1}$ is $A_{11}$ and $x_{2}$ is $B_{11}$, then $y$ is $C_{11}$ else Rule 12: if $x_{1}$ is $A_{12}$ and $x_{2}$ is $B_{12}$, then $y$ is $C_{12}$ else Rule 13: if $x_{1}$ is $A_{13}$ and $x_{2}$ is $B_{13}$, then $y$ is $C_{13}$ else Rule 14: if $x_{1}$ is $A_{14}$ and $x_{2}$ is $B_{14}$, then $y$ is $C_{14}$ else Rule 15: if $x_{1}$ is $A_{15}$ and $x_{2}$ is $B_{15}$, then $y$ is $C_{15}$ else Rule 16: if $x_{1}$ is $A_{16}$ and $x_{2}$ is $B_{16}$, then $y$ is $C_{16}$ else Rule 17: if $x_{1}$ is $A_{17}$ and $x_{2}$ is $B_{17}$, then $y$ is $C_{17}$ else Rule 18: if $x_{1}$ is $A_{18}$ and $x_{2}$ is $B_{18}$, then $y$ is $C_{18}$ else Rule 19: if $x_{1}$ is $A_{19}$ and $x_{2}$ is $B_{19}$, then $y$ is $C_{19}$ else Rule 20: if $x_{1}$ is $A_{20}$ and $x_{2}$ is $B_{20}$, then $y$ is $C_{20}$ else Rule 21: if $x_{1}$ is $A_{21}$ and $x_{2}$ is $B_{21}$, then $y$ is $C_{21}$ else Rule 22: If $x_{1}$ is $A_{22}$ and $x_{2}$ is $B_{22}$, then $y$ is $C_{22}$ else Rule 23: If $x_{1}$ is $A_{23}$ and $x_{2}$ is $B_{23}$, then $y$ is $C_{23}$ else Rule 24: If $x_{1}$ is $A_{24}$ and $x_{2}$ is $B_{24}$, then $y$ is $C_{24}$ else Rule 25: If $x_{1}$ is $A_{25}$ and $x_{2}$ is $B_{25}$, then $y$ is $C_{25}$ else Rule 26: If $x_{1}$ is $A_{26}$ and $x_{2}$ is $B_{26}$, then $y$ is $C_{26}$ else Rule 27: If $x_{1}$ is $A_{27}$ and $x_{2}$ is $B_{27}$, then $y$ is $C_{27}$,

where $A_{i}, B_{i}$, and $C_{i}(i=1,2, \ldots, 27)$ are fuzzy sets modeled using membership functions $\mu_{A}, \mu_{B}$, and $\mu_{C}$, respectively, while $x_{1}$ and $x_{2}$ are the input variables and $y$ is the output variable.

In this paper, the max-min compositional operation of Mamdani was adopted to perform the calculation of fuzzy logic reasoning. The Mamdani implication method was used, and the fuzzy logic reasoning of these rules then achieved a fuzzy output. The membership function $\mu_{C_{0}}(y)$ of the output of the fuzzy logic reasoning could be expressed as follows [50]:

$$
\begin{aligned}
\mu_{C_{0}}(y)= & \left(\mu_{A_{1}}\left(x_{1}\right) \wedge \mu_{B_{1}}\left(x_{2}\right)\right) \vee \cdots \\
& \vee\left(\mu_{A_{27}}\left(x_{1}\right) \wedge \mu_{B_{27}}\left(x_{2}\right)\right),
\end{aligned}
$$

where $\wedge$ is the minimum operation and $\vee$ is the maximum operation.

Finally, the fuzzy output was converted into an absolute value using the defuzzification method. In this study, the center of gravity method for defuzzification was utilized to transform the fuzzy inference output $\mu_{C_{0}}(y)$ into a nonfuzzy value $y_{0}$ (MPI). MPI was then used to search for the optimal parameters. In general, the value of MPI lies within the range of 0 and 1 . This study carried out the proposed steps in toolbox MATLAB (2014a) with the Mamdani method. The nonfuzzy value $y_{0}$, the MPI, was calculated by following equation [51]:

$$
\text { MPI }=\frac{\sum y \mu_{C_{0}}(y)}{\sum \mu_{C_{0}}(y)} .
$$

Step 10 (the response table and response graph of grey-fuzzy reasoning grade). Through the Taguchi method, the optimal parameters were determined via constructing the response table and response graph of grey-fuzzy reasoning grade (GFRG).
Step 11 (calculate ANOVA for grey relational reasoning grade). Analysis of variance (ANOVA) was used to estimate the significant contribution of each factor on the grey relational reasoning grade.

Step 12 (predict the optimal grey-fuzzy reasoning grade under optimum parameters). The optimal grey-fuzzy reasoning grade was predicted considering the effect of all parameters or the most significant parameter. The estimated mean of the grey relational grade could be determined as

$$
\mu_{\mathrm{GFRG}}=\mathrm{GFRG}_{\mathrm{m}}+\sum_{s=1}^{q}\left(\mathrm{GFRG}_{\mathrm{o}}-\mathrm{GFRG}_{\mathrm{m}}\right) \text {, }
$$

where $\mu_{\mathrm{GFRG}}$ is the optimal GFRG value of predicted mean, $\mathrm{GFRG}_{\mathrm{m}}$ is the total mean of grey-fuzzy reasoning grade, GFRG $_{\mathrm{o}}$ is the optimal mean grey-fuzzy reasoning grade for each level of factor, and $q$ is the number of significant parameters affecting the grey-fuzzy reasoning grade.

In order to judge the closeness of the observed value to the predicted value, the confidence interval value of the predicted value for the optimum factor level combination was determined. The 95\% confidence interval of confirmation experiments $\left(\mathrm{CI}_{\mathrm{CE}}\right)$ was calculated using the following expression [43]:

$$
\mathrm{CI}_{\mathrm{CE}}= \pm \sqrt{F_{\alpha}\left(1, f_{\mathrm{e}}\right) V_{\mathrm{e}}\left(\frac{1}{n_{\mathrm{eff}}}+\frac{1}{R_{\mathrm{e}}}\right)}
$$

where $\alpha=$ risk $=0.05 ; F_{\alpha}\left(1, f_{\mathrm{e}}\right)=F_{0.05}\left(1, f_{\mathrm{e}}\right)$ is the $F$-ratio at 95\% $(1-\alpha)$ confidence interval against degrees of freedom 1 and degrees of freedom of error $f_{\mathrm{e}} ; V_{\mathrm{e}}$ is the variance of error (get from ANOVA), $n_{\text {eff }}=n /(1+d) ; n$ is the total trial number in the orthogonal array; $d$ is the total degrees of freedom of factors associated in estimates of the mean $\mu_{\mathrm{GFRG}}$; and $R_{\mathrm{e}}$ is the number of repetitions for the confirmation experiments.

Step 13 (confirmation experiments). Many prototypes were fabricated via wire electrical discharged machining process. The confirmation experimentations were then carried out to validate the optimal results.

\section{Results and Discussion}

4.1. Experimental Measurement of Quality Responses. The relationship between the design variables and quality characteristics of CGM was discussed to determine the optimal design variables. First, the composition of various factors and level values was designed through the Taguchi method, as given in Table 4. As mentioned, CGM required a broad displacement and a high first natural frequency; this study therefore selected the type of the higher-the better for two responses according to the Taguchi method. With five process parameters and three levels, the experimental plan was designed via using the orthogonal array $L_{27}$, as seen in Table 5. The 27 experiments were conducted to measure the displacement and first natural frequency. The experimental instruments were installed on a vibration isolated optical 
TABLE 4: Controlling factors and their levels.

\begin{tabular}{lcccc}
\hline Symbol & $\begin{array}{c}\text { Process } \\
\text { parameters }\end{array}$ & Level 1 & Level 2 & Level 3 \\
\hline$F$ & Force (N) & 180.0 & 180.2 & 180.4 \\
$L$ & Length (mm) & 40.0 & 40.2 & 40.4 \\
$W$ & Width (mm) & 30.0 & 30.2 & 30.4 \\
$T$ & Thickness (mm) & 2.2 & 2.4 & 2.6 \\
$R$ & Filleted radius & 0.4 & 0.6 & 0.8 \\
\hline
\end{tabular}

TABLE 5: Experimental layout using an $L_{27}$ orthogonal array.

\begin{tabular}{|c|c|c|c|c|c|}
\hline $\begin{array}{l}\text { Trial } \\
\text { number }\end{array}$ & Force $F$ & Length $L$ & Width $W$ & Thickness $T$ & $\begin{array}{c}\text { Filleted } \\
\text { radius } R\end{array}$ \\
\hline 1 & 180.0 & 40.0 & 30.0 & 2.2 & 0.4 \\
\hline 2 & 180.0 & 40.0 & 30.2 & 2.4 & 0.6 \\
\hline 3 & 180.0 & 40.0 & 30.4 & 2.6 & 0.8 \\
\hline 4 & 180.0 & 40.2 & 30.0 & 2.4 & 0.6 \\
\hline 5 & 180.0 & 40.2 & 30.2 & 2.6 & 0.8 \\
\hline 6 & 180.0 & 40.2 & 30.4 & 2.2 & 0.4 \\
\hline 7 & 180.0 & 40.4 & 30.0 & 2.6 & 0.8 \\
\hline 8 & 180.0 & 40.4 & 30.2 & 2.2 & 0.4 \\
\hline 9 & 180.0 & 40.4 & 30.4 & 2.4 & 0.6 \\
\hline 10 & 180.2 & 40.0 & 30.0 & 2.4 & 0.8 \\
\hline 11 & 180.2 & 40.0 & 30.2 & 2.6 & 0.4 \\
\hline 12 & 180.2 & 40.0 & 30.4 & 2.2 & 0.6 \\
\hline 13 & 180.2 & 40.2 & 30.0 & 2.6 & 0.4 \\
\hline 14 & 180.2 & 40.2 & 30.2 & 2.2 & 0.6 \\
\hline 15 & 180.2 & 40.2 & 30.4 & 2.4 & 0.8 \\
\hline 16 & 180.2 & 40.4 & 30.0 & 2.2 & 0.6 \\
\hline 17 & 180.2 & 40.4 & 30.2 & 2.4 & 0.8 \\
\hline 18 & 180.2 & 40.4 & 30.4 & 2.6 & 0.4 \\
\hline 19 & 180.4 & 40.0 & 30.0 & 2.6 & 0.6 \\
\hline 20 & 180.4 & 40.0 & 30.2 & 2.2 & 0.8 \\
\hline 21 & 180.4 & 40.0 & 30.4 & 2.4 & 0.4 \\
\hline 22 & 180.4 & 40.2 & 30.0 & 2.2 & 0.8 \\
\hline 23 & 180.4 & 40.2 & 30.2 & 2.4 & 0.4 \\
\hline 24 & 180.4 & 40.2 & 30.4 & 2.6 & 0.6 \\
\hline 25 & 180.4 & 40.4 & 30.0 & 2.4 & 0.4 \\
\hline 26 & 180.4 & 40.4 & 30.2 & 2.6 & 0.6 \\
\hline 27 & 180.4 & 40.4 & 30.4 & 2.2 & 0.8 \\
\hline
\end{tabular}

table (DAEIL systems, model: DVIO-I-1209M-100t, Korea) to avoid any unexpected vibrations. The prototypes were fabricated via using wire electrical discharged machining process.

The experimental set-up of displacement is demonstrated in Figure 5. The calibration instruments included a force gage (Lutron, tension and compression, maximum 196 N, DC 9V adapter, model: NF-9500, Taiwan) to adjust the force value and an indicator (MITUTOYO, code number 7010s, Japan). The prototype was mounted on a base fixed on the vibration isolation system table. The measuring head of the indicator was adjusted to touch the end effector of the CGM. The indicator would display the value of displacement in millimeters. The value would be recorded in each experiment. Four experiments were conducted on the prototype and the final displacement result was the average value of the four experiments.

The experimental photograph of first natural frequency is shown in Figure 6. The measurements of the first natural frequency within the range of $500 \mathrm{~Hz}$ to $5 \mathrm{kHz}$ were performed to evaluate the dynamic characteristics of the mechanism. A modal hammer (model 9722A2000-SN 2116555) from KISTLER was used to apply the excitation to the mechanism, and the frequency response was measured by using an accelerator (model 4744892) from KISTLER. The accelerator was attached at location that was opposite the excitation position of the hammer. A modal analyzer (model NI USB 9162) from National Instruments was utilized in data acquisition and analysis. At the end of the hammer, a force sensor was attached to measure the applied force from the hammer. CUTPRO software was installed in a computer to analyze the data. The experiments were repeated five times. All experimental data and signal to noise ratios of two responses were collected and calculated, as seen in Table 6.

4.2. Multiresponse Optimization. The principle of optimization process in this paper was conducted as follows: the $S / N$ ratios were calculated for each response by using (8) and the normalized $S / N$ values were firstly computed via (9). The deviation sequence was determined via (10) and the grey relational coefficient (GRC) of each response was then determined by (11). Subsequently, the grey relational coefficients (GRCs) would be imported into fuzzy logic system to achieve a grey-fuzzy reasoning grade (GFRG) through (12)-(14). Last, via the Taguchi method, the response table and response graph of GFRG were established to achieve the optimal parameters.

Recalling (8)-(11) again, $k$ in bracket $(k)$ represented the various responses. The displacement response was corresponding to $k=1$ while the frequency response was corresponding to $k=2$. Specifically, $z_{i}(1)$ was the normalized $S / N$ ratio of displacement and $z_{i}(2)$ was the normalized $S / N$ ratio of frequency. $\Delta_{o i}(1)$ and $\Delta_{o i}(2)$ were deviation sequences of displacement and frequency, respectively. $\gamma_{i}(1)$ and $\gamma_{i}(2)$ were grey relational coefficients of deviation sequences of displacement and frequency, respectively. In this paper, $\Delta_{\text {min }}$ was equal to zero (the smallest value of $\Delta_{o i}$ ); $\Delta_{\max }$ was equal to one (the largest value of $\Delta_{o i}$ ).

In this paper, two inputs and one output were used for the fuzzy logic system. The inference engine (Mamdani fuzzy inference system) performed fuzzy reasoning with fuzzy rules to generate a fuzzy value. These fuzzy rules were presented in the form of "if-then" control rule, as in the proposed methodology. As mentioned in Section 3, the nine fuzzy subsets were used for GRC of displacement, the three fuzzy subsets for GRC of frequency, and the nine fuzzy subsets for the output GFRG. The 27 fuzzy rules were then established in a matrix form for this study, as given in Table 7. The corresponding membership functions for the two inputs were 


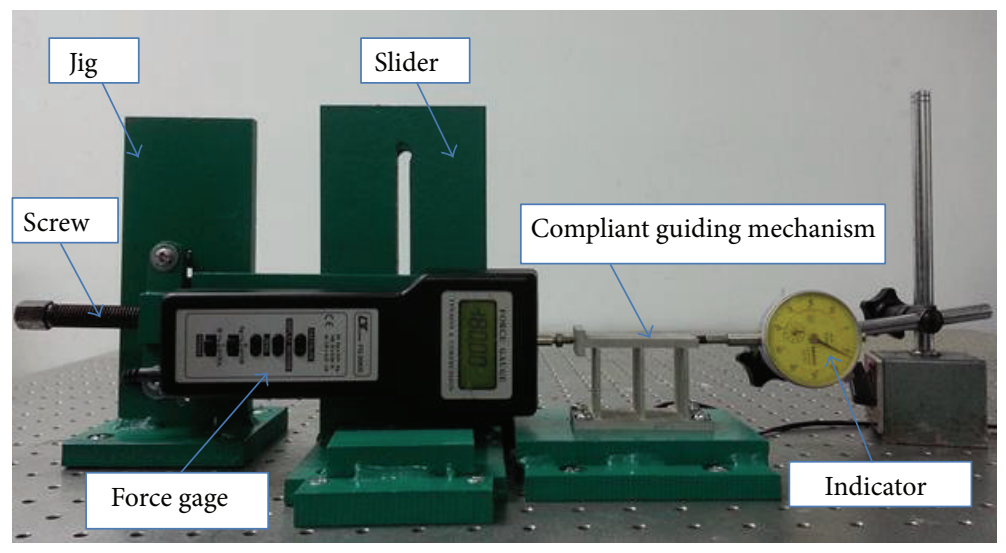

FIGURE 5: Experimental measurement of the displacement response.

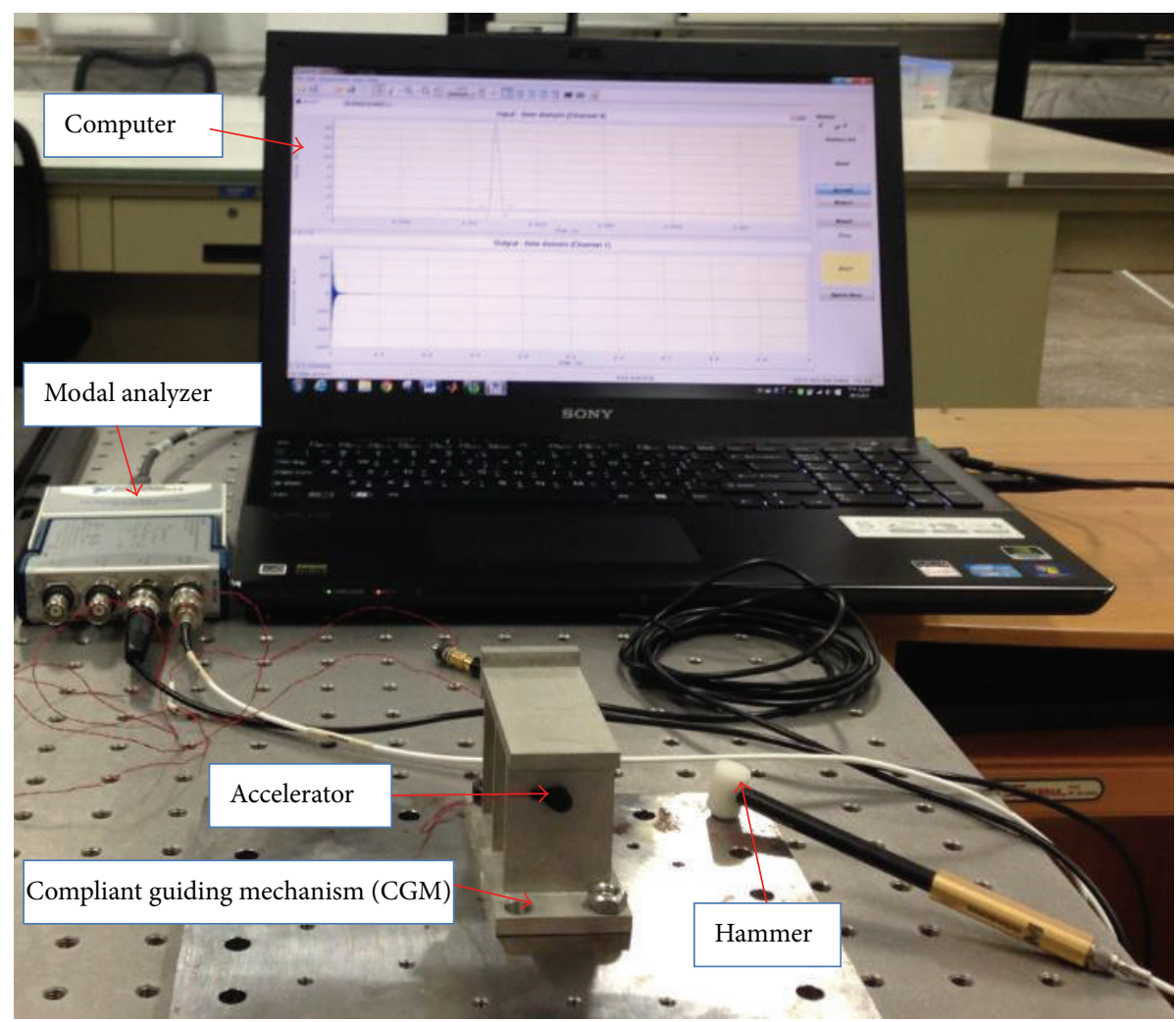

FIGURE 6: Experimental measurement of the first natural frequency response.

$\mu_{x 1}$ and $\mu_{x 2}$, respectively. The membership function of the output was $\mu_{y}$. The membership functions of the GRC of displacement and GRC of frequency were plotted in Figures $7(\mathrm{a})$ and $7(\mathrm{~b})$, respectively. The membership function of output GFRG was given in Figure 8.

Fuzzy rules were directly derived based on the fact of "the higher-the better" characteristic. The rule based fuzzy logic reasoning procedure was developed, as seen in Figure 9. As developed, the twenty-seven rows represented twentyseven fuzzy rules and the two first columns denoted two input variables, that is, GRC for displacement and frequency, respectively. The last column gave the defuzzified grey-fuzzy reasoning grade (GFRG). By tracking maximum-minimum compositional operation, the fuzzy reasoning of these rules yielded a fuzzy output. Finally, the defuzzifier converted the fuzzy predicted value into a GFRG by using MATLAB (R2014a) fuzzy logic toolbox.

To sum up, Table 8 provides the difference sequences, grey relational coefficients, and GFRG for two responses. The higher value of GFRG means that the comparability sequence had a stronger correlation to the reference sequence.

Based on the Taguchi method, the average grey-fuzzy reasoning grade for each input parameter level was calculated in Table 9. The response graph for average GFRG at parameter 
TABLE 6: Experimental results and $S / N$ ratios of two responses.

\begin{tabular}{|c|c|c|c|c|}
\hline Trial number & $y_{1}(\mathrm{~mm})$ & $S / N$ of $y_{1}$ & $y_{2}(\mathrm{~Hz})$ & $S / N$ of $y_{2}$ \\
\hline 1 & 0.12978 & -17.7358 & 915.69820 & 59.2350 \\
\hline 2 & 0.12896 & -17.7909 & 918.86598 & 59.2650 \\
\hline 3 & 0.13090 & -17.6612 & 911.54112 & 59.1955 \\
\hline 4 & 0.13091 & -17.6605 & 914.64157 & 59.2250 \\
\hline 5 & 0.12891 & -17.7943 & 915.79683 & 59.2360 \\
\hline 6 & 0.12823 & -17.8402 & 924.12678 & 59.3146 \\
\hline 7 & 0.13104 & -17.6519 & 913.44788 & 59.2137 \\
\hline 8 & 0.08983 & -20.9316 & 1093.03575 & 60.7727 \\
\hline 9 & 0.19508 & -14.1957 & 760.34755 & 57.6202 \\
\hline 10 & 0.12970 & -17.7412 & 915.69820 & 59.2350 \\
\hline 11 & 0.12985 & -17.7312 & 915.69820 & 59.2350 \\
\hline 12 & 0.11579 & -18.7266 & 968.74378 & 59.7242 \\
\hline 13 & 0.11621 & -18.6951 & 966.72673 & 59.7061 \\
\hline 14 & 0.11531 & -18.7627 & 968.80407 & 59.7247 \\
\hline 15 & 0.11581 & -18.7251 & 966.78696 & 59.7066 \\
\hline 16 & 0.11642 & -18.6794 & 963.89005 & 59.6805 \\
\hline 17 & 0.11727 & -18.6163 & 960.30546 & 59.6482 \\
\hline 18 & 0.11602 & -18.7093 & 963.94997 & 59.6811 \\
\hline 19 & 0.11679 & -18.6519 & 960.36520 & 59.6487 \\
\hline 20 & 0.14555 & -16.7398 & 869.16617 & 58.7821 \\
\hline 21 & 0.14650 & -16.6832 & 866.33494 & 58.7537 \\
\hline 22 & 0.14505 & -16.7696 & 869.21885 & 58.7826 \\
\hline 23 & 0.14591 & -16.7183 & 866.38743 & 58.7542 \\
\hline 24 & 0.14649 & -16.6838 & 867.98192 & 58.7702 \\
\hline 25 & 0.14713 & -16.6460 & 865.86430 & 58.7490 \\
\hline 26 & 0.14589 & -16.7195 & 868.03470 & 58.7707 \\
\hline 27 & 0.14662 & -16.6761 & 865.91688 & 58.7495 \\
\hline
\end{tabular}

TABLE 7: Fuzzy rules in a matrix form.

\begin{tabular}{lccc}
\hline $\begin{array}{l}\text { Grey-fuzzy reasoning } \\
\text { grade (GFRG) }\end{array}$ & \multicolumn{3}{c}{ GRC of frequency } \\
\hline $\begin{array}{cccc}\text { GRC of displacement } \\
\text { T }\end{array}$ & T (rule 1) & VS (rule 2) & S (rule 3) \\
VS & VS (rule 4) & S (rule 5) & SM (rule 6) \\
S & S (rule 7) & SM (rule 8) & ML (rule 9) \\
SM & S (rule 10) & SM (rule 11) & M (rule 12) \\
M & SM (rule 13) & M (rule 14) & ML (rule 15) \\
ML & SM (rule 16) & M (rule 17) & ML (rule 18) \\
L & ML (rule 19) & ML (rule 20) & L (rule 21) \\
VL & ML (rule 22) & L (rule 23) & VL (rule 24) \\
H & ML (rule 25) & L (rule 26) & H (rule 27) \\
\hline
\end{tabular}

level was plotted as in Figure 10. The results from Table 9 and Figure 10 indicated that the optimal input parameter level is F1L3W3T2R2 corresponding to the applied force at level $1(180.0 \mathrm{~N})$, the length at level $3(40.4 \mathrm{~mm})$, the width at level $3(30.4 \mathrm{~mm})$, the thickness at level $2(2.4 \mathrm{~mm})$, and the filleted radius at level $2(0.6 \mathrm{~mm})$. The results predicted that the maximum displacement is equal to $0.195 \mathrm{~mm}$ and the maximum first natural frequency is equal to $760.34 \mathrm{~Hz}$.
TABLE 8: Data of each sequence, difference sequence, grey relational coefficient, and GFRG.

\begin{tabular}{lccccccc}
\hline Number & $z_{i}(1)$ & $z_{i}(2)$ & $\Delta_{o i}(1)$ & $\Delta_{o i}(2)$ & $\gamma_{i}(1)$ & $\gamma_{i}(2)$ & GFRG \\
\hline 1 & 0.4744 & 0.5122 & 0.5256 & 0.4878 & 0.4875 & 0.5062 & 0.303 \\
2 & 0.4663 & 0.5218 & 0.5337 & 0.4782 & 0.4837 & 0.5111 & 0.295 \\
3 & 0.4855 & 0.4997 & 0.5145 & 0.5003 & 0.4929 & 0.4999 & 0.312 \\
4 & 0.4856 & 0.5091 & 0.5144 & 0.4909 & 0.4929 & 0.5046 & 0.314 \\
5 & 0.4658 & 0.5125 & 0.5342 & 0.4875 & 0.4834 & 0.5063 & 0.293 \\
6 & 0.4589 & 0.5375 & 0.5411 & 0.4625 & 0.4803 & 0.5195 & 0.290 \\
7 & 0.4869 & 0.5055 & 0.5131 & 0.4945 & 0.4935 & 0.5027 & 0.314 \\
8 & 0.0000 & 1.0000 & 1.0000 & 0.0000 & 0.3333 & 1.0000 & 0.250 \\
9 & 1.0000 & 0.0000 & 0.0000 & 1.0000 & 1.0000 & 0.3333 & 0.625 \\
10 & 0.4736 & 0.5122 & 0.5264 & 0.4878 & 0.4872 & 0.5062 & 0.302 \\
11 & 0.4751 & 0.5122 & 0.5249 & 0.4878 & 0.4879 & 0.5062 & 0.304 \\
12 & 0.3274 & 0.6674 & 0.6726 & 0.3326 & 0.4264 & 0.6005 & 0.235 \\
13 & 0.3320 & 0.6617 & 0.6680 & 0.3383 & 0.4281 & 0.5964 & 0.237 \\
14 & 0.3220 & 0.6676 & 0.6780 & 0.3324 & 0.4244 & 0.6007 & 0.231 \\
15 & 0.3276 & 0.6618 & 0.6724 & 0.3382 & 0.4265 & 0.5965 & 0.233 \\
16 & 0.3344 & 0.6536 & 0.6656 & 0.3464 & 0.4289 & 0.5907 & 0.236 \\
17 & 0.3437 & 0.6433 & 0.6563 & 0.3567 & 0.4324 & 0.5836 & 0.240 \\
18 & 0.3299 & 0.6537 & 0.6701 & 0.3463 & 0.4273 & 0.5908 & 0.232 \\
19 & 0.3384 & 0.6435 & 0.6616 & 0.3565 & 0.4305 & 0.5837 & 0.236 \\
20 & 0.6223 & 0.3685 & 0.3777 & 0.6315 & 0.5697 & 0.4419 & 0.289 \\
21 & 0.6307 & 0.3596 & 0.3693 & 0.6404 & 0.5752 & 0.4384 & 0.288 \\
22 & 0.6179 & 0.3687 & 0.3821 & 0.6313 & 0.5668 & 0.4420 & 0.289 \\
23 & 0.6255 & 0.3597 & 0.3745 & 0.6403 & 0.5718 & 0.4385 & 0.288 \\
24 & 0.6306 & 0.3648 & 0.3694 & 0.6352 & 0.5751 & 0.4404 & 0.289 \\
25 & 0.6362 & 0.3581 & 0.3638 & 0.6419 & 0.5789 & 0.4379 & 0.287 \\
26 & 0.6253 & 0.3650 & 0.3747 & 0.6350 & 0.5716 & 0.4405 & 0.289 \\
27 & 0.6318 & 0.3582 & 0.3682 & 0.6418 & 0.5759 & 0.4379 & 0.287 \\
\hline & & & & & & &
\end{tabular}

TABLE 9: Response table for the mean GFRG for each parameter level.

\begin{tabular}{lccccc}
\hline \multirow{2}{*}{ Factor } & \multicolumn{3}{c}{ Mean of GFRG for each level } & \multirow{2}{*}{ Max-min } & Rank \\
& Level 1 & Level 2 & Level 3 & & \\
\hline$F$ & 0.333 & 0.250 & 0.282 & 0.083 & 1 \\
$L$ & 0.285 & 0.274 & 0.307 & 0.033 & 4 \\
$W$ & 0.280 & 0.275 & 0.310 & 0.035 & 3 \\
$T$ & 0.268 & 0.319 & 0.278 & 0.051 & 2 \\
$R$ & 0.275 & 0.306 & 0.284 & 0.031 & 5 \\
\multicolumn{7}{c}{ Total mean value of GFRG is 0.288 } \\
\hline
\end{tabular}

The optimal results were corresponding to the 9 th experiment with a highest GFRG of 0.625 (see Tables 6 and 8). It was also proven that the best quality characteristics are capable of corresponding to the highest GFRG.

4.3. ANOVA for Grey-Fuzzy Reasoning Grade. ANOVA was performed to understand the influence of design parameters on the quality characteristics. Table 10 shows that factor $F$ (applied force) has the most significant influence on the target characteristics with percentage contribution of $51.86 \%$, followed by factor $L$ (length) with percentage $5.60 \%$. Factors 


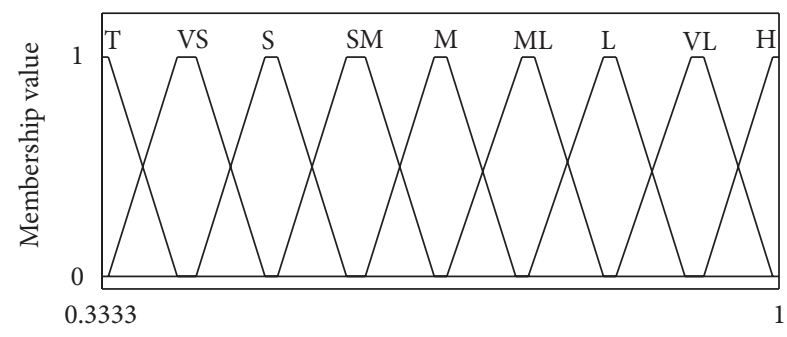

(a)

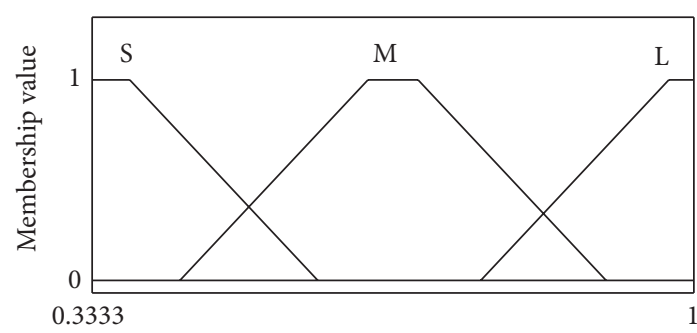

(b)

FIGURE 7: Membership function of two inputs: (a) GRC of displacement $\gamma_{i}(1)$ and (b) GRC of frequency $\gamma_{i}(2)$.

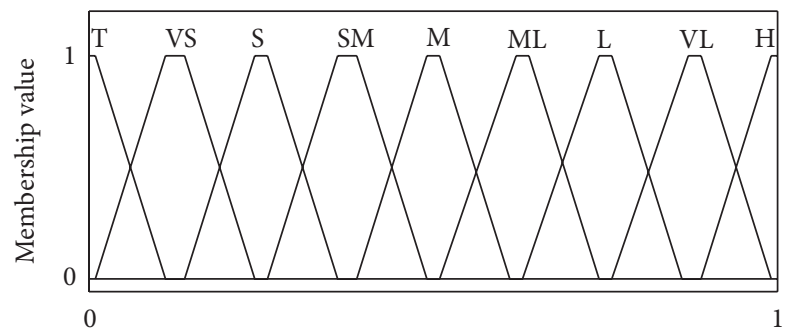

Figure 8: Membership function of output (GFRG).

TABLE 10: ANOVA for GFRG.

\begin{tabular}{lccccc}
\hline Factors & DOF & SS & $V$ & $F$ & $P(\%)$ \\
\hline$F$ & 2 & 0.0588 & 0.0294 & 10.8931 & 51.86 \\
$L$ & 2 & 0.0063 & 0.0032 & 1.1710 & 5.60 \\
$W$ & 2 & 0.0020 & $10^{-4}$ & 0.3657 & 1.75 \\
$T$ & 2 & 0.0018 & $10^{-4}$ & 0.3318 & 1.60 \\
$R$ & 2 & 0.0013 & $10^{-4}$ & 0.2452 & 1.20 \\
Error & 16 & 0.0431 & 0.0027 & & 37.99 \\
Total & 26 & & & 100 \\
\multicolumn{5}{c}{ Significant at 95\% confidence level. } \\
\hline
\end{tabular}

$W$ (width), $T$ (thickness), and $R$ (filleted radius) have lowest influences with $1.75 \%, 1.60 \%$, and $1.20 \%$, respectively.

4.4. Predict the Optimal Grey-Fuzzy Grade under Optimum Parameters. In this study, the optimal grey-fuzzy reasoning grade was predicted considering the effect of all controlling parameters at optimal level F1L3W3T2R2. The estimated mean of the GFRG was determined by (15), and then $95 \%$ confidence interval of confirmation experiments $\left(\mathrm{CI}_{\mathrm{CE}}\right)$ was calculated using (16). The expected mean value of confirmation experiments was obtained as $\mu_{\mathrm{GFRG}}=0.423$.

The confirmation value $\mu_{\text {confirmation }}$ of the GFRG should fall within the range as follows:

$$
\begin{gathered}
\mu_{\mathrm{GFRG}}-\mathrm{CI}_{\mathrm{CE}} \leq \mu_{\text {confirmation }} \leq \mu_{\mathrm{GFRG}}+\mathrm{CI}_{\mathrm{CE}}, \\
0.189 \leq \mu_{\text {confirmation }} \leq 0.657 .
\end{gathered}
$$

TABLE 11: Confirmation results.

\begin{tabular}{lccc}
\hline Responses & Predicted value & FEM value & Error\% \\
\hline Displacement & $0.195 \mathrm{~mm}$ & $0.203 \mathrm{~mm}$ & $4.1 \%$ \\
Frequency & $760.34 \mathrm{~Hz}$ & $780.86 \mathrm{~Hz}$ & $2.6 \%$ \\
GFRG & 0.625 & 0.654 & $4.6 \%$ \\
\hline
\end{tabular}

\subsection{Confirmation Experiments}

4.5.1. Optimal Confirmation. By using optimal combination F1L3W3T2R2, four confirmation experiments were performed to validate the optimal results. The experimental results of Table 11 revealed that the confirmation GFRG results fall within $95 \%$ of the $\mathrm{CI}_{\mathrm{CE}}$ (see (17)).

Four models at optimal combination F1L3W3T2R2 were constructed in Solidworks and conducted by finite element method (FEM) in ANSYS to validate the optimal results. The results showed that the error between FEM result and predicted value is less than $5 \%$, as seen in Table 11 . It means that the proposed methodology is reliable to predict the optimal parameters of CGM. Reasons may come from the following: (1) manufacturing error leads to dimensional errors between the analysis model and the prototype and (2) the used parameters in the simulation may be different from the actual materials.

As mentioned, a larger displacement would result in a broader indentation depth for any indentation device. Hence, the displacement of various guiding mechanisms for indentation devices was searched for the purpose of comparison. Compared with the existing guiding mechanisms for indentation devices in the literature review, the displacement of CGM had the following highlights: as seen in Table 12, the displacement of CGM was 8.75 times larger than that of [15], 15.25 times larger than that of [19], and 12 times higher than that of [20]. It could be concluded that the displacement of CGM is tremendously improved via the hybrid Taguchi-grey based fuzzy logic approach.

4.5.2. Validation of Stress Constraint. Figure 11 demonstrates the experimental photo to measure the actual strain of the CGM. The calibration instruments included a force gage (Lutron, tension and compression, maximum $196 \mathrm{~N}$, DC 9V adapter, model: NF-9500, Taiwan) to adjust the applied force, a sensor gage (KFG 5-120-C1-11L1M2R, KYOWA, 
GRC of displacement

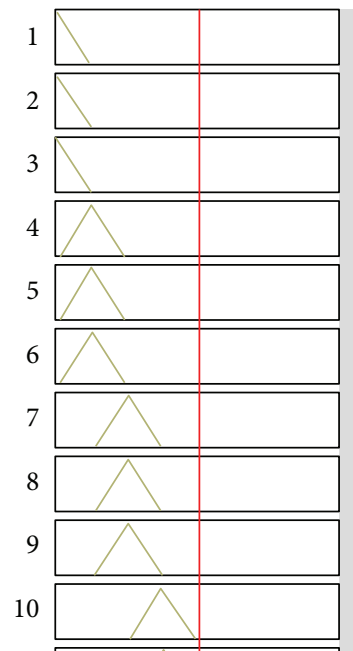

11

12

13

14

15

16

17

18

19

20

21

22

23

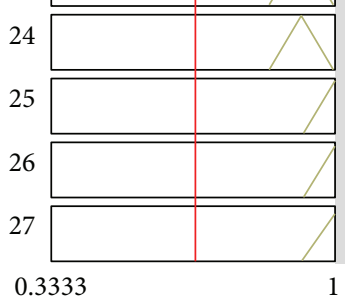

GRC of frequency
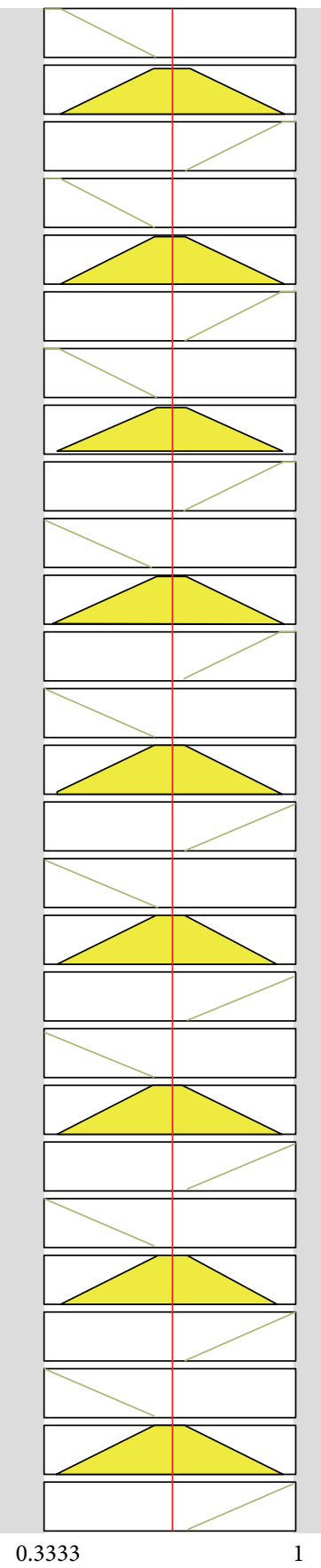

GFRG

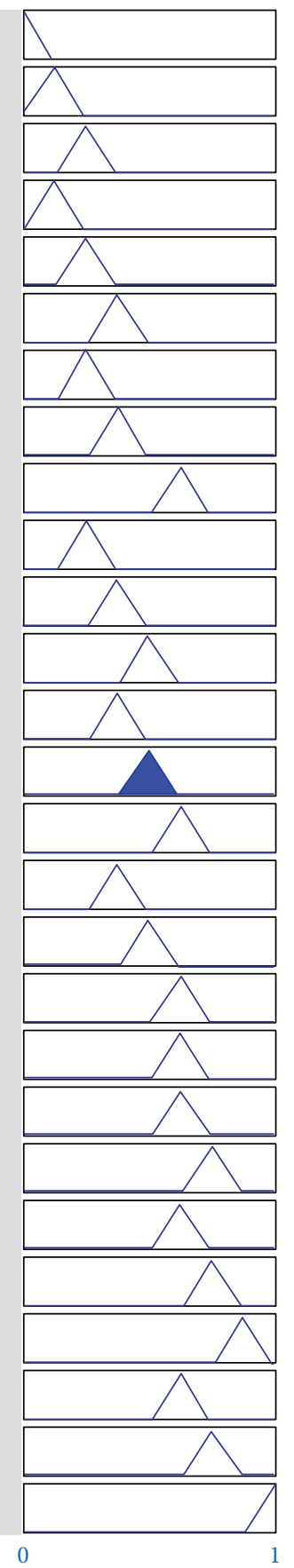

Figure 9: Fuzzy logic reasoning procedure.

Japan), a CPU (computer processing unit, ASUS), DAQ (data acquisition, National International Instrument, Japan), and a screen (ASUS). The prototype of CGM using optimal combination F1L3W3T2R2 was mounted onto a base that was fixed onto the vibration isolation system table. There were three sensor gages. A sensor gage was glued at each flexure hinge of the CGM to measure the actual strain. Each flexure hinge was measured separately.
The experiment for each flexure hinge was repeated four times. The force gage was adjusted to gradually reach a value of $180 \mathrm{~N}$. Data from the sensor gage was transferred into the DAQ instrument, which generated data into the CPU. LABVIEW $^{\circledR}$ software was set up in the CPU so that the strain wave and value of the strain were displayed on the screen. The strain value after each experimental measure was recorded. The final actual strain of the CGM was the average value of 
TABLE 12: Comparison the displacement of GCM with previous mechanisms.

\begin{tabular}{lc}
\hline Mechanisms & Displacement $(\mu \mathrm{m})$ \\
\hline The CGM & 195 \\
Reference [15] & 12 \\
Reference [19] & 15 \\
Reference [20] & 20 \\
\hline
\end{tabular}

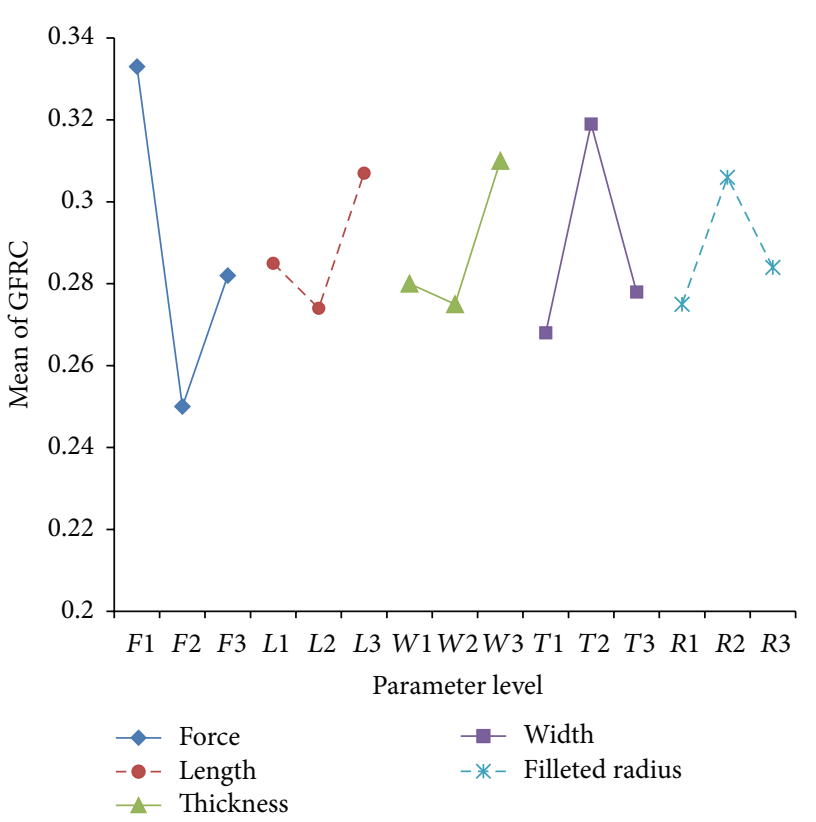

FIGURE 10: Response graph of grey-fuzzy reasoning grade.

all the experiments. The actual stress value of the CGM was calculated using the following equation:

$$
\sigma=\varepsilon \times E,
$$

where $\sigma$ is the actual stress; $\varepsilon$ is the mean actual strain; and $E$ is Young's modulus of the proposed material.

The results indicated that the maximum real stress $(40.63 \mathrm{MPa})$ is still much lower than the yield strength of aluminum alloy 6061-T651 (780 MPa). This actual stress was close to the FEM equivalent stress $(38.54 \mathrm{MPa})$ with an error of $5.1 \%$. It could be concluded that the maximum stress satisfied the constraint in (6). This could deduced that the flexure hinge is safe during the working process. The optimization process was ended.

\section{Preliminary Application for Microindentation Testing}

A preliminary model of microindentation device was developed, as depicted in Figure 12(a). It consists of the following components: (1) compliant guiding mechanism (CGM), (2) load sensor, (3) stage, (4) specimen, (5) indenter, (6) indenter holder, (7) displacement sensor, (8) reflector, (9) coarse positioner, and (10) base. The specimen is driven by the proposed CGM towards the fixed indenter. The coarse positioner is driven by a stepper motor to realize a coarse adjustment of the specimen. During the indentation tests, the load and displacement are measured by the load sensor and displacement sensor through the reflector, respectively. The base makes a tilt angle $\alpha$ of 15 degrees from the platform of SEM to provide a good observation angle during indentation.

At the beginning, the specimen is positioned at a suitable location by the coarse positioner, and then the CGM is activated by the applied force and the specimen will move toward the indenter, and then the indentation process is finished. As seen in Figure 12(b), the proposed CGM is driven by an appropriate actuator in the $x$-axis to realize the precise loading and unloading of the indenter. During the testing, the load sensor and the displacement sensor are used to measure the applied load and the displacement response.

Because of the $195 \mu \mathrm{m}$ broad displacement and the $760.34 \mathrm{~Hz}$ high first-order frequency, the proposed mechanism has potential applications under large indentation depth-and-high frequency conditions. It could be concluded that the CGM is an excellent candidate for indentation device inside the SEM. A real indentation testing will be devoted for prospective work.

\section{Conclusions}

This study has attempted to optimize the multiple quality responses for a compliant guiding mechanism (CGM). The CGM was designed for future micro/nanoindentation devices inside a scanning electron microscope (SEM). It aimed to guide the specimen towards the fixed indenter.

The displacement and first natural frequency were considered as the most important quality responses of CGM. The force exerted on CGM and geometric parameters of flexure hinges were the design variables. Through parasitic error analysis in FEM, the CGM had an excellent behavior of single-axis translation along the $x$-direction.

Firstly, the effect of design variables on the two responses was analyzed via the response surface methodology inside ANSYS. The results indicated that the force, length, width, thickness, and filleted radius are significantly affecting the two responses.

Secondly, the experimental layout was then conducted by the $L_{27}$ orthogonal array of Taguchi method. Many prototypes of CGM were fabricated via wire electric discharged machining process. And then the experimentations were carried out to collect data of two responses.

Lastly, a hybrid approach of Taguchi-grey based fuzzy logic was developed to optimize the displacement and first natural frequency, simultaneously. At the beginning phase, the $S / N$ ratios of two responses were calculated and the normalized $S / N$ values were subsequently computed. The deviation sequence was determined and the grey relational coefficient (GRC) of each response was then calculated. The GRCs were then imported into fuzzy logic system to achieve a grey-fuzzy reasoning grade (GFRG). Based on the Taguchi method, the response table and response graph of GFRG were constructed and the optimal design parameters were achieved. ANOVA was performed to determine the significant parameters affecting the grey-fuzzy reasoning 


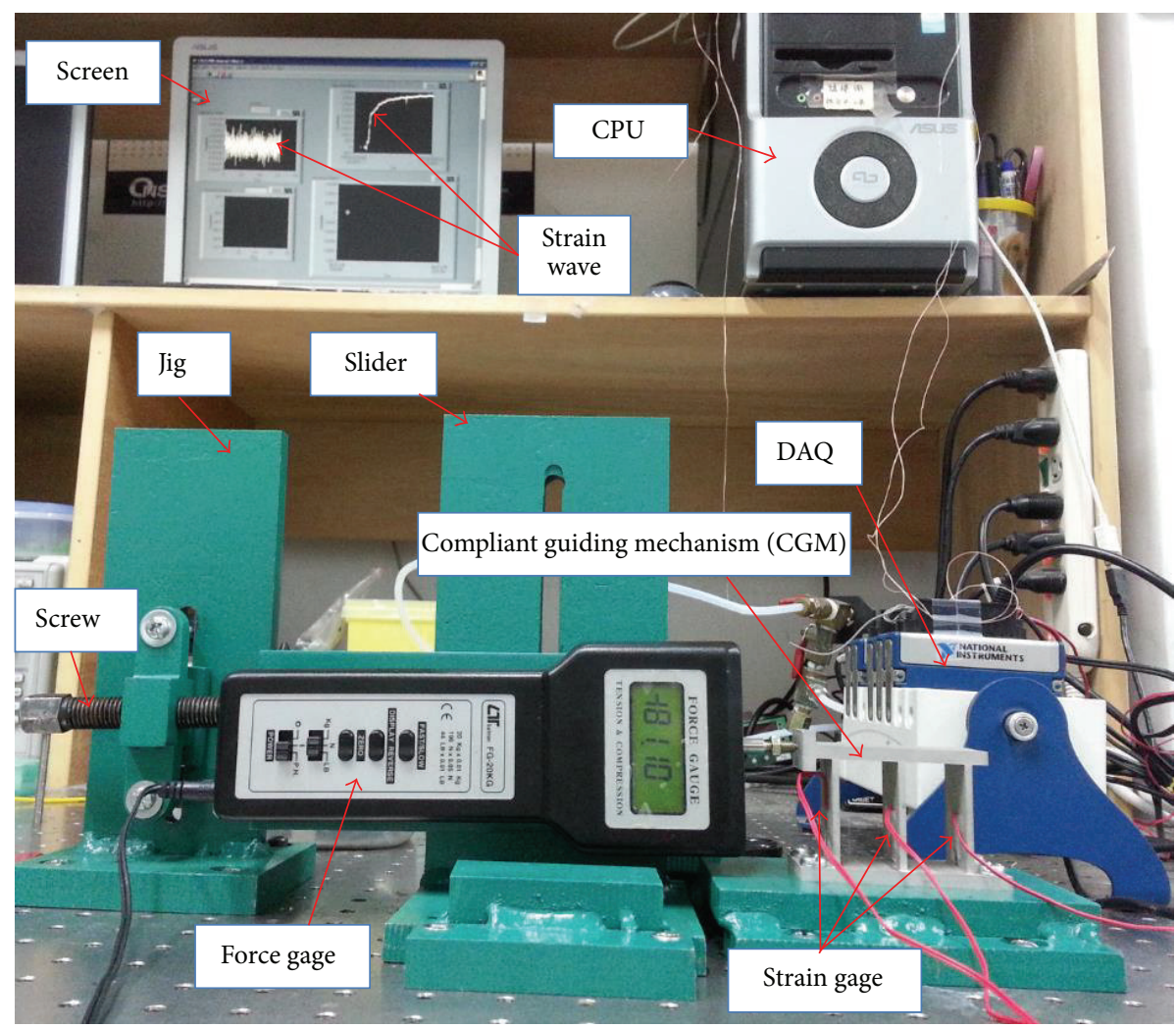

FIgURE 11: Photo of the experimental strain.

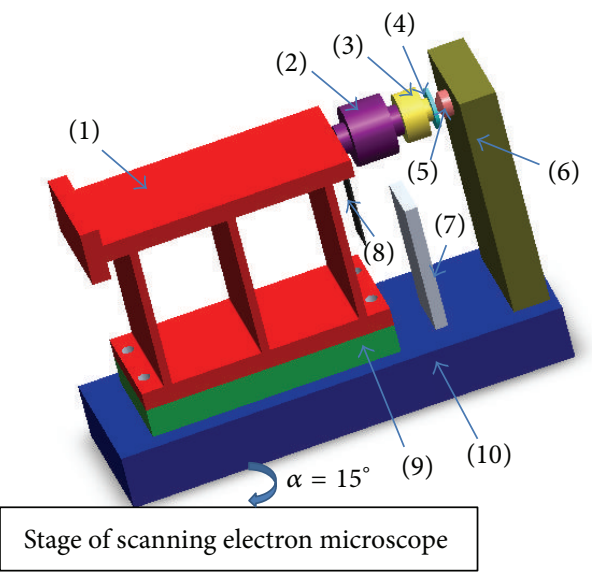

(1) Compliant guiding mechanism (CGM)

(2) Load sensor

(3) Stage

(4) Specimen

(5) Indenter

(6) Indenter holder

(7) Displacement sensor

(8) Reflector

(9) Coarse positioner

(10) Base

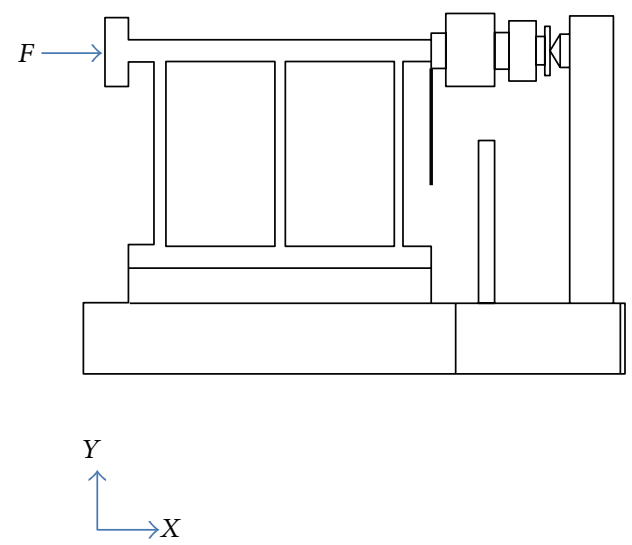

(a)

(b)

FIgURe 12: (a) Preliminary model of indentation device and (b) 2D view. 
grade (GFRG). The results revealed that the applied force is the most significant factor.

The confirmation results indicated that the $195 \mu \mathrm{m}$ displacement of the CGM was many times greater than the other mechanisms in the literature review. The quality responses of the CGM could be extremely enhanced through the proposed approach. The efficiency of methodology has been successfully proven by experiments and simulations. It is useful for related compliant mechanisms and engineering sciences. Taking the advantages of a compact structure into account, the proposed mechanism can construct a compact micro/nanoindentation device inside SEM.

\section{Competing Interests}

The author declares that there are no competing interests regarding the publication of this paper.

\section{References}

[1] M. K. Kang, B. Li, P. S. Ho, and R. Huang, "Buckling of single-crystal silicon nanolines under indentation," Journal of Nanomaterials, vol. 2008, Article ID 132728, 11 pages, 2008.

[2] L. Liu, G. Cao, and X. Chen, "Mechanisms of nanoindentation on multiwalled carbon nanotube and nanotube cluster," Journal of Nanomaterials, vol. 2008, Article ID 271763, 12 pages, 2008.

[3] J. Gao, G. Dai, J. Zhao, H. Li, L. Xu, and Z. Zhu, "Influence of indentation on the fatigue strength of carbonitrided plain steel," Advances in Materials Science and Engineering, vol. 2015, Article ID 492693, 9 pages, 2015.

[4] Z. Tang, Y. Guo, Z. Jia, Y. Li, and Q. Wei, "Examining the effect of pileup on the accuracy of sharp indentation testing," Advances in Materials Science and Engineering, vol. 2015, Article ID 528729, 10 pages, 2015.

[5] R. Machaka, T. E. Derry, I. Sigalas, and M. Herrmann, "Analysis of the indentation size effect in the microhardness measurements in $\mathrm{B}_{6} \mathrm{O}$," Advances in Materials Science and Engineering, vol. 2011, Article ID 539252, 6 pages, 2011.

[6] L. C. Hui, J. C. Pei, W. H. Bo, and H. K. Jao, "Young's moduli of human tooth measured using micro-indentation tests," Life Science Journal, vol. 9, pp. 172-177, 2012.

[7] J. Dean, J. Campbell, G. A. Smith, and T. W. Clyne, "Critical assessment of the stable indenter velocity method for obtaining the creep stress exponent from indentation data," Acta Materialia, vol. 80, pp. 56-66, 2014.

[8] T. H. Zhang, Y. H. Feng, R. Yang, and P. Jiang, "A method to determine fracture toughness using cube-corner indentation," Scripta Materialia, vol. 62, no. 4, pp. 199-201, 2010.

[9] J. M. Antunes, J. V. Fernandes, L. F. Menezes, and B. M. Chaparro, "A new approach for reverse analyses in depth-sensing indentation using numerical simulation," Acta Materialia, vol. 55, no. 1, pp. 69-81, 2007.

[10] H. Huang and H. Zhao, "In situ nanoindentation and scratch testing inside scanning electron microscopes: opportunities and challenges," Science of Advanced Materials, vol. 6, no. 5, pp. 875889, 2014.

[11] S. Balos, L. Sidjanin, and B. Pilic, "Indentation size effect in autopolymerized and microwave post treated poly(methyl methacrylate) denture reline resins," Acta Polytechnica Hungarica, vol. 11, no. 7, pp. 239-249, 2014.
[12] J. Z. Zhang, M. M. Michalenko, E. Kuhl, and T. C. Ovaert, "Characterization of indentation response and stiffness reduction of bone using a continuum damage model," Journal of Thermal Mechanical Behavior of Biomedical Materials, vol. 3, pp. 189-202, 2010.

[13] C. Ciofu and G. Creţu, "Some aspects concerning the micro indentation on testing of ultramid plastic materials," International Journal of Modern Manufacturing Technologies, vol. 6, pp. 2067-3604, 2014.

[14] S. Amiri, N. Lecis, A. Manes, and M. Giglio, "A study of a microindentation technique for estimating the fracture toughness of Al6061-T6," Mechanics Research Communications, vol. 58, pp. 10-16, 2014.

[15] R. Rabe, J.-M. Breguet, P. Schwaller et al., "Observation of fracture and plastic deformation during indentation and scratching inside the scanning electron microscope," Thin Solid Films, vol. 469-470, pp. 206-213, 2004.

[16] N. A. Sakharova, J. V. Fernandes, J. M. Antunes, and M. C. Oliveira, "Comparison between Berkovich, Vickers and conical indentation tests: a three-dimensional numerical simulation study," International Journal of Solids and Structures, vol. 46, no. 5, pp. 1095-1104, 2009.

[17] W. G. Mao, Y. G. Shen, and C. Lu, "Deformation behavior and mechanical properties of polycrystalline and single crystal alumina during nanoindentation," Scripta Materialia, vol. 65, no. 2, pp. 127-130, 2011.

[18] R. Ghisleni, K. Rzepiejewska-Malyska, L. Philippe, P. Schwaller, and J. Michler, "In situ SEM indentation experiments: Instruments, methodology, and applications," Microscopy Research and Technique, vol. 72, no. 3, pp. 242-249, 2009.

[19] H. Huang, H. Zhao, Z. Ma et al., "Design and analysis of the precision-driven unit for nano-indentation and scratch test," Journal of Manufacturing Systems, vol. 31, no. 1, pp. 76-81, 2012.

[20] H. Zhao, H. Huang, Z. Yang, Z. Ma, and Z. Fan, Design, Analysis and Experiments of a Novel in situ SEM Indentation Device, vol. 12, chapter 12, INTECH, 2012.

[21] L. L. Howell, Compliant Mechanisms, John Wiley \& Sons, New York, NY, USA, 2001.

[22] R. S. Kumar, K. Sureshkumar, and R. Velraj, "Optimization of biodiesel production from Manilkara zapota (L.) seed oil using Taguchi method," Fuel, vol. 140, pp. 90-96, 2015.

[23] H. Tanyildizi and M. Şahin, "Application of Taguchi method for optimization of concrete strengthened with polymer after high temperature," Construction and Building Materials, vol. 79, pp. 97-103, 2015.

[24] T. Du, W. Du, K. Che, and L. Cheng, "Parametric optimization of overlapped helical baffled heat exchangers by Taguchi method," Applied Thermal Engineering, vol. 85, pp. 334-339, 2015.

[25] P. Asokan, R. R. Kumar, R. Jeyapaul, and M. Santhi, "Development of multi-objective optimization models for electrochemical machining process," International Journal of Advanced Manufacturing Technology, vol. 39, no. 1-2, pp. 55-63, 2008.

[26] Y. S. Tarng, S. C. Juang, and C. H. Chang, "The use of grey-based Taguchi methods to determine submerged arc welding process parameters in hardfacing," Journal of Materials Processing Technology, vol. 128, no. 1-3, pp. 1-6, 2002.

[27] J. L. Deng, "Grey information space," The Journal of Grey System, vol. 1, no. 2, pp. 103-117, 1989.

[28] S. Ilo, C. Just, and F. Xhiku, "Optimisation of multiple quality characteristics of hardfacing using grey-based Taguchi method," Materials \& Design, vol. 33, no. 1, pp. 459-468, 2012. 
[29] R. K. Pandey and S. S. Panda, "Multi-performance optimization of bone drilling using Taguchi method based on membership function," Measurement, vol. 59, pp. 9-13, 2015.

[30] S. Roy, A. K. Das, and R. Banerjee, "Application of GreyTaguchi based multi-objective optimization strategy to calibrate the PM-NHC-BSFC trade-off characteristics of a CRDI assisted CNG dual-fuel engine," Journal of Natural Gas Science and Engineering, vol. 21, pp. 524-531, 2014.

[31] U. Çaydaş and A. Hasçalik, "Use of the grey relational analysis to determine optimum laser cutting parameters with multiperformance characteristics," Optics \& Laser Technology, vol. 40, no. 7, pp. 987-994, 2008.

[32] M.-J. Tsai and C.-H. Li, "The use of grey relational analysis to determine laser cutting parameters for QFN packages with multiple performance characteristics," Optics \& Laser Technology, vol. 41, no. 8, pp. 914-921, 2009.

[33] L. A. Zadeh, "Fuzzy sets," Information and Computation, vol. 8, pp. 338-353, 1965.

[34] C. Chen, G. G. Rigatos, D. Dong, and J. Lam, "Partial feedback control of quantum systems using probabilistic fuzzy estimator," in Proceedings of the 48th IEEE Conference on Decision and Control, Held Jointly with the 28th Chinese Control Conference (CDC/CCC '09), pp. 3805-3810, IEEE, Shanghai, China, December 2009.

[35] C. Chen and T. Xiao, "Probabilistic fuzzy control of mobile robots for range sensor based reactive navigation," Intelligent Control and Automation, vol. 2, pp. 77-85, 2011.

[36] S. Chen and C. Chen, "Probabilistic fuzzy system for uncertain localization and map building of mobile robots," IEEE Transactions on Instrumentation and Measurement, vol. 61, no. 6, pp. 1546-1560, 2012.

[37] Y.-H. Chang, C.-L. Chen, W.-S. Chan, H.-W. Lin, and C.-W. Chang, "Fuzzy formation control and collision avoidance for multiagent systems," Mathematical Problems in Engineering, vol. 2013, Article ID 908180, 18 pages, 2013.

[38] Y.-F. Tzeng and F.-C. Chen, "Multi-objective optimisation of high-speed electrical discharge machining process using a Taguchi fuzzy-based approach," Materials and Design, vol. 28, no. 4, pp. 1159-1168, 2007.

[39] A. K. Pandey and A. K. Dubey, “Taguchi based fuzzy logic optimization of multiple quality characteristics in laser cutting of Duralumin sheet," Optics and Lasers in Engineering, vol. 50, no. 3, pp. 328-335, 2012.

[40] N.-M. Liu, J.-T. Horng, and K.-T. Chiang, "The method of greyfuzzy logic for optimizing multi-response problems during the manufacturing process: a case study of the light guide plate printing process," International Journal of Advanced Manufacturing Technology, vol. 41, no. 1-2, pp. 200-210, 2009.

[41] R. K. Pandey and S. S. Panda, "Optimization of bone drilling parameters using grey-based fuzzy algorithm," Measurement, vol. 47, no. 1, pp. 386-392, 2014.

[42] Y.-S. Yang and W. Huang, "A grey-fuzzy Taguchi approach for optimizing multi-objective properties of zirconium-containing diamond-like carbon coatings," Expert Systems with Applications, vol. 39, no. 1, pp. 743-750, 2012.

[43] T. Rajmohan, K. Palanikumar, and S. Prakash, "Grey-fuzzy algorithm to optimise machining parameters in drilling of hybrid metal matrix composites," Composites Part B: Engineering, vol. 50, pp. 297-308, 2013.

[44] A. K. Pandey and A. K. Dubey, "Multiple quality optimization in laser cutting of difficult-to-laser-cut material using grey-fuzzy methodology," International Journal of Advanced Manufacturing Technology, vol. 65, no. 1, pp. 421-431, 2013.

[45] H. S. Lu, J. Y. Chen, and C. T. Chung, "The optimal cutting parameter design of rough cutting process in side milling," Journal of Achievements in Materials and Manufacturing, vol. 29, pp. 183-186, 2008.

[46] K.-T. Chiang and F.-P. Chang, "Application of grey-fuzzy logic on the optimal process design of an injection-molded part with a thin shell feature," International Communications in Heat and Mass Transfer, vol. 33, no. 1, pp. 94-101, 2006.

[47] C. Ahilan, S. Kumanan, and N. Sivakumaran, "Multi-objective optimisation of CNC turning process using grey based fuzzy logic," International Journal of Machining and Machinability of Materials, vol. 5, no. 4, pp. 434-451, 2009.

[48] J.-H. Yeh and T.-N. Tsai, "Optimizing the fine-pitch copper wire bonding process with multiple quality characteristics using a grey-fuzzy Taguchi method," Microelectronics Reliability, vol. 54, no. 1, pp. 287-296, 2014.

[49] ANSYS, ANSYS Workbench User's Guide, ANSYS, Canonsburg, $\mathrm{Pa}, \mathrm{USA}, 2015$.

[50] M. J. Wierman, Fuzzy Sets, Fuzzy Logic, and Control, Center of Mathematics of Uncertainty, Inc, Omaha, Nebraska, 2008.

[51] G. J. Klir and B. Yuan, Fuzzy Sets and Fuzzy Logic: Theory and Applications, Prentice Hall, New Delhi, India, 3rd edition, 2005. 


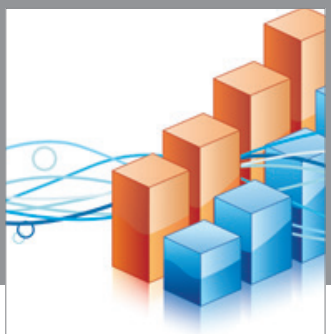

Advances in

Operations Research

vatem alat4

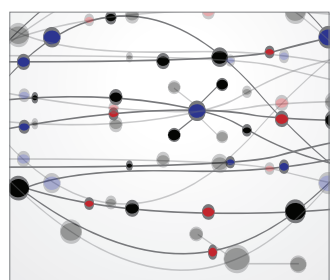

\section{The Scientific} World Journal
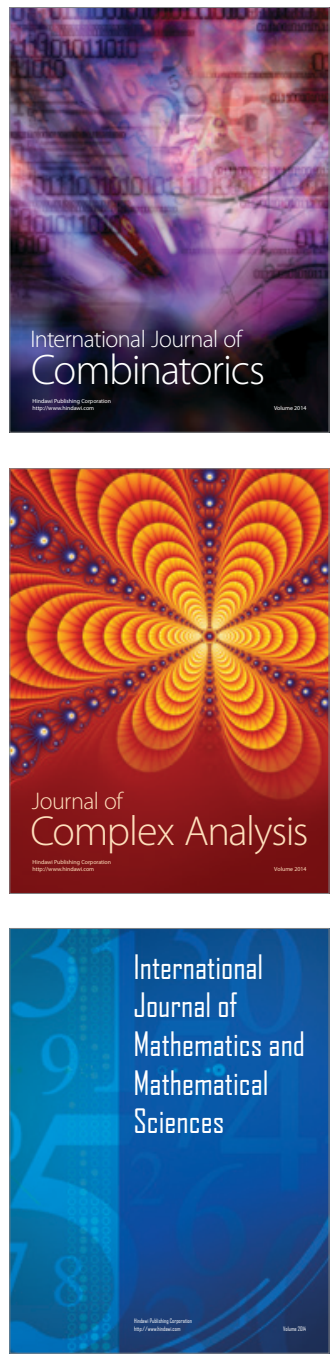
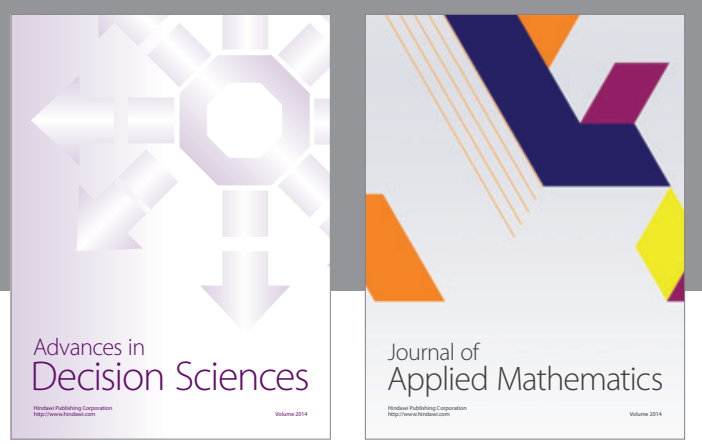

Algebra

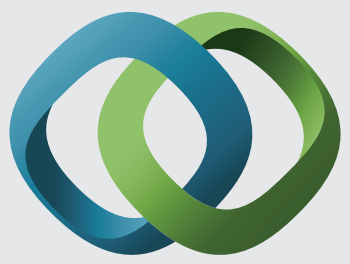

\section{Hindawi}

Submit your manuscripts at

http://www.hindawi.com
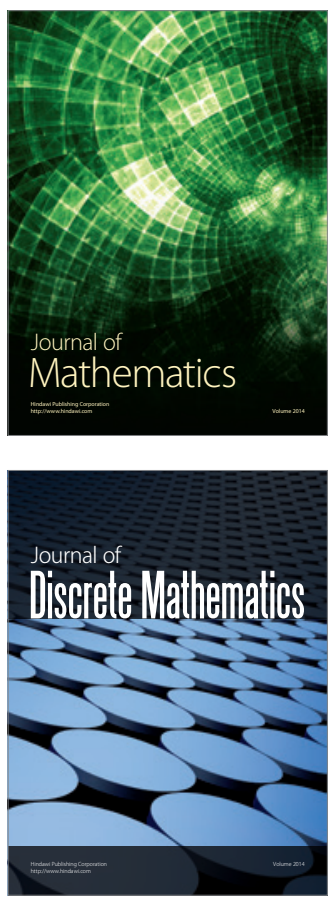

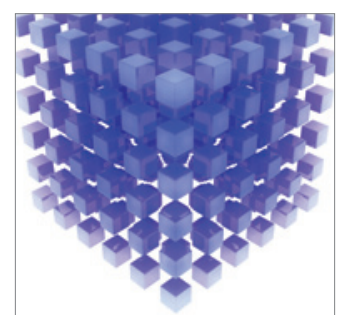

Mathematical Problems in Engineering
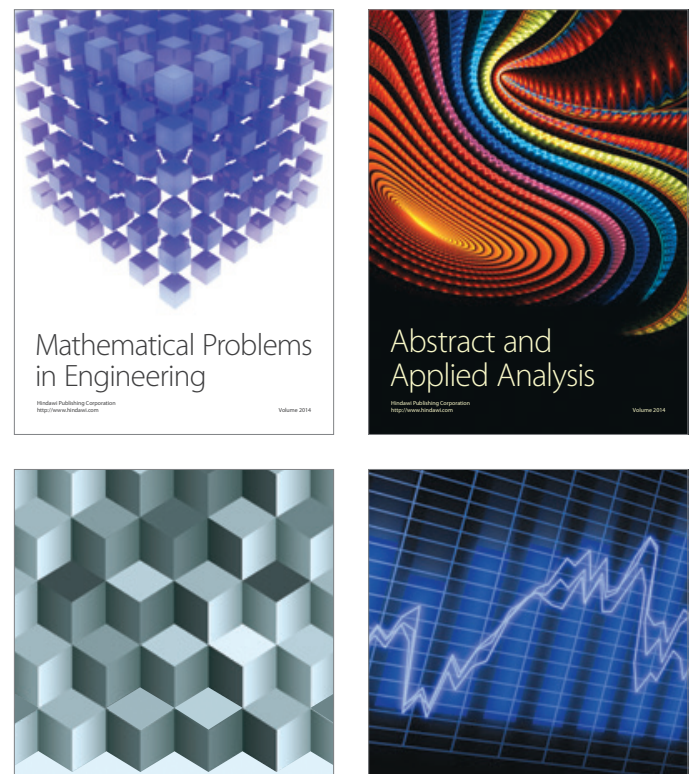

Journal of

Function Spaces

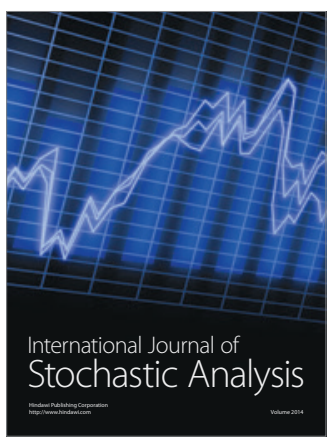

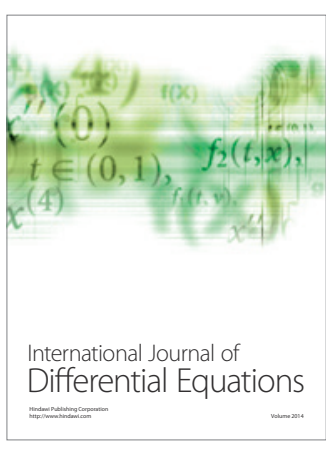
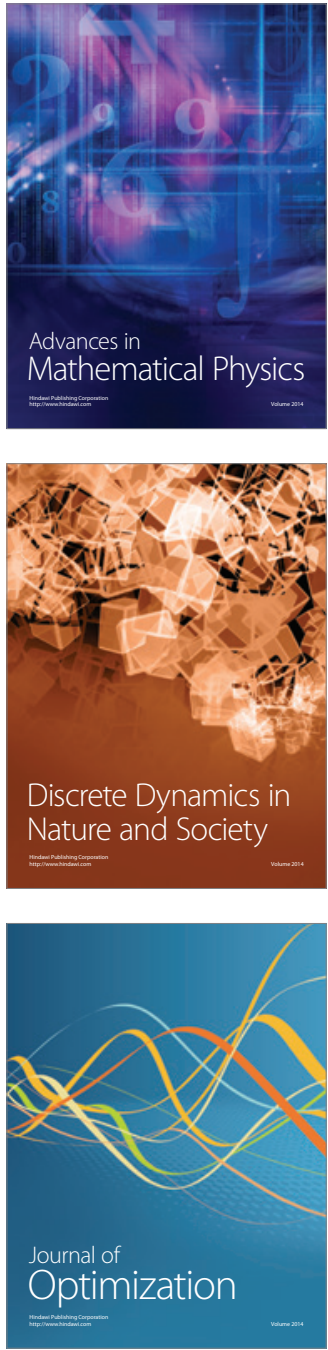